\title{
البرناهج التاسع
}

\section{تطوير السياسات المالية والإدارية}

\author{
إعداد

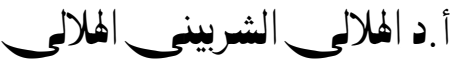 \\ أستاذ التخطيط التربوي والإدارة التعليمية بجامعة المنصورة \\ ووزير التربية والتعليهم والتعليمم الفني السـابق
}

مجلة بحوث التربية النوعية ـ جامعة المنصورة

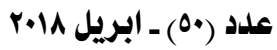

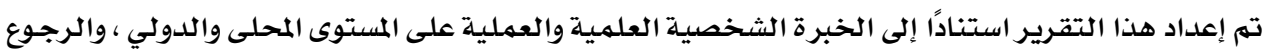

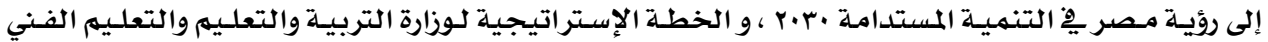

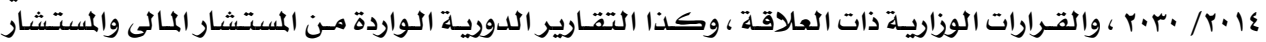

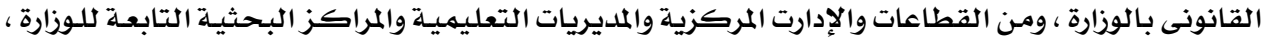

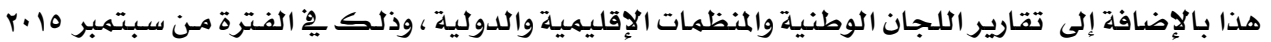

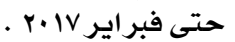




\section{البرناهم التاسع \\ تطوير السياسات المالية والإدارية}

إعداد

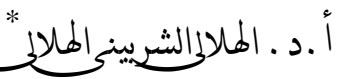

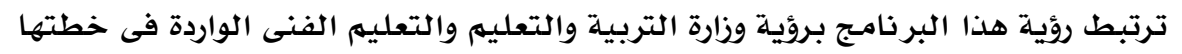

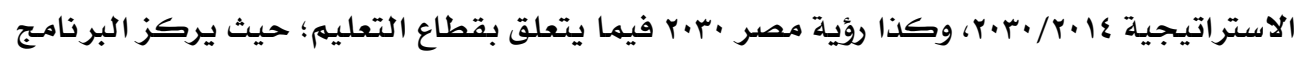

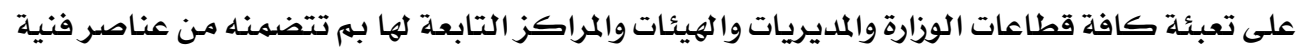

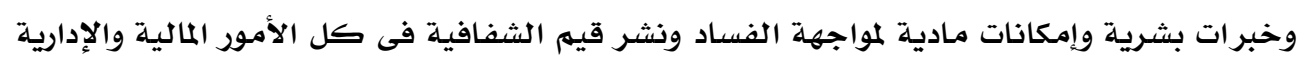

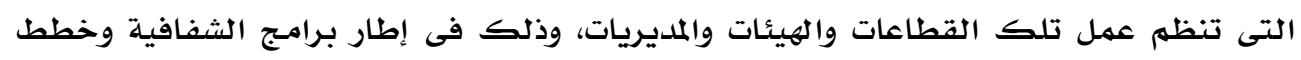

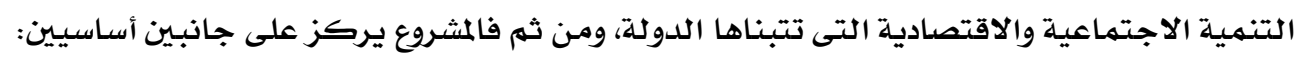

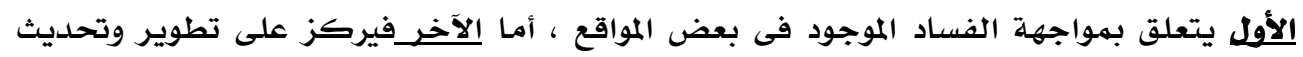

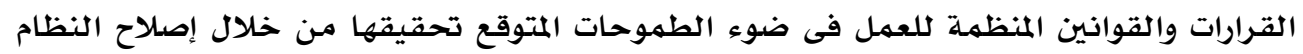

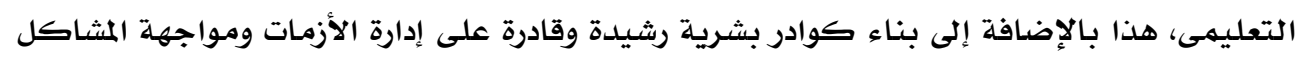

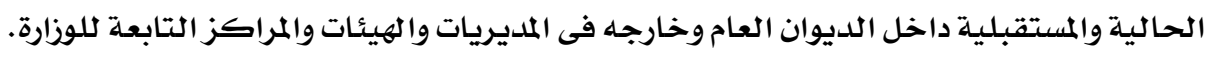
وسوف يتهم عرض ما تم من هذا البرنامج من خلال حصر وتحديد الوضع الراهن

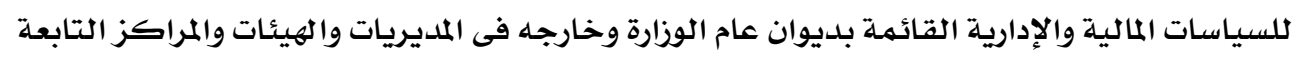

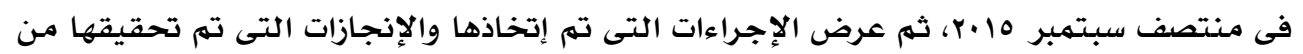

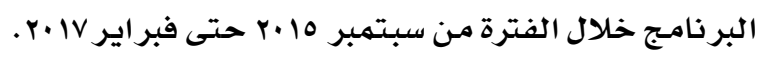

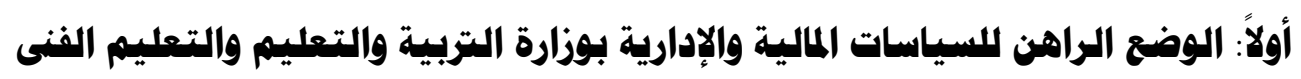

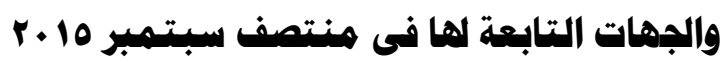

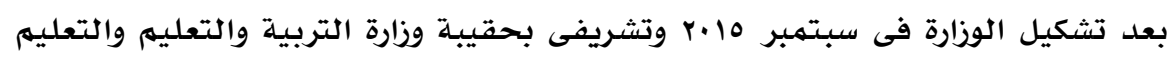

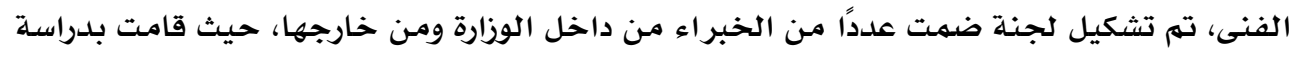

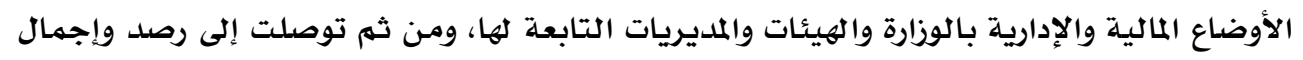

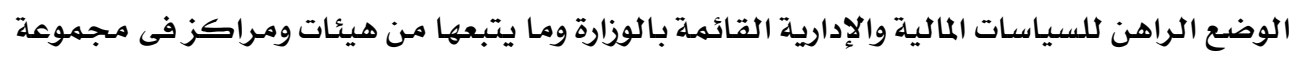

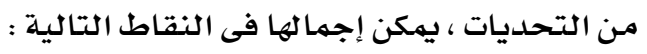

أستاذ التخطيط التربوي والإدارة التعليمية بجامعة المنصورة ووزير التربيـة والتعليهم والتعليم الفني السـابق 
ا. عدم وجود آلية حديثة لتقييم آداء مديرى المراكز والهيئات التابعة للوزارة، وكذا رؤساء

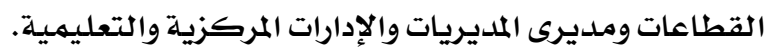

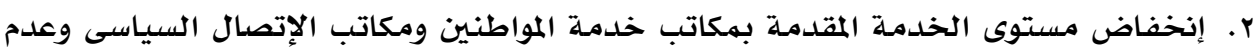
كفايتها على المستويات المختلفة. r. وجود خلل فى الهيكل التتظيمى للإدارة المركزية للمتابعة وتقويم الأداء بديوان عام الوزارة

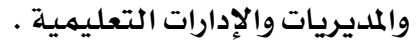

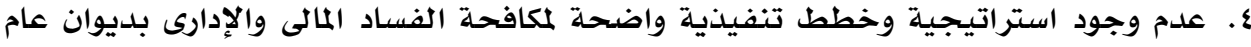
الوزارة والمديريات التعليمية. ه. وجود خلل كبير فى توزيع المعلمين داخل المديريات والإدارات التعليمية وإنتداب عدد كبيدير كبير منهم على وظائف إدارية . 7. عدم الإستخدام الأمثل لأصول وممتلكات الوزارة ووجود قصور في ترشيد الإستهلاك، وفى تنمية

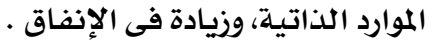
V. الحاجة الضرورية لتعديل بعض القرارات الجمهورية والقرارات الوزارية والقوانية وانين المنظمهة

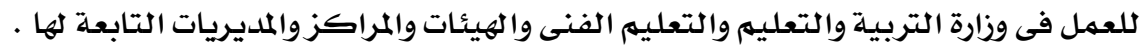

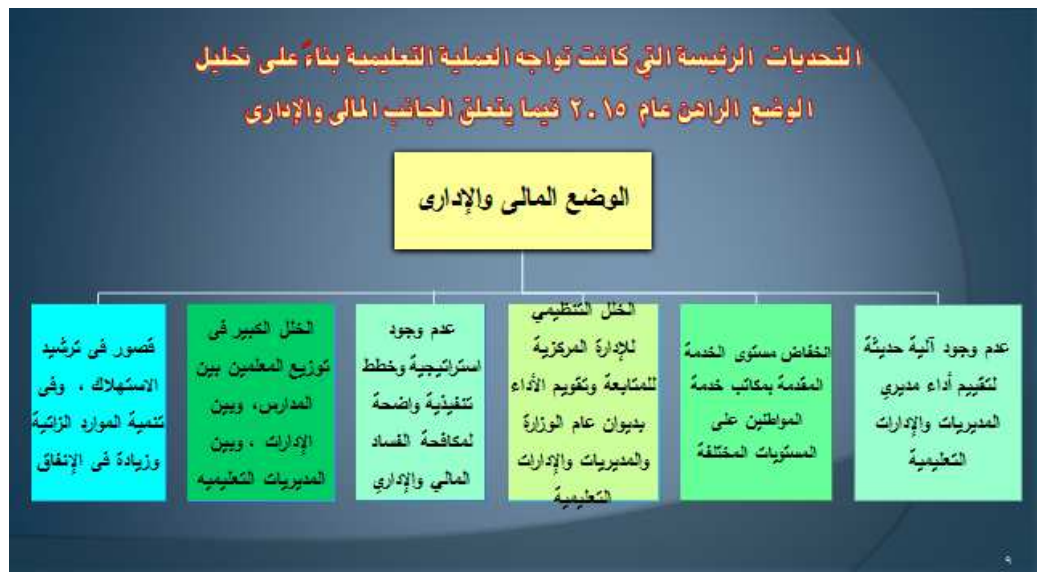

ثانيا: الإجراءات التى اتهذت والإنهازات التى تم تمقيقها فى البرناهمج

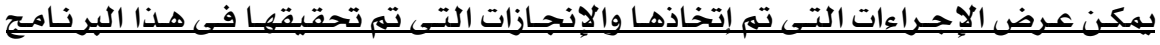

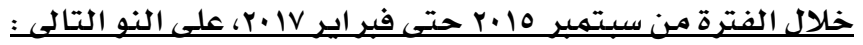
ا. بالنسبة لعدم وجود آلية حليثة لتقييم آداء مديرى الملديريات التعليمية ووكلائها، وكذا مديرى الإدارات التعليمية ووكلائها.

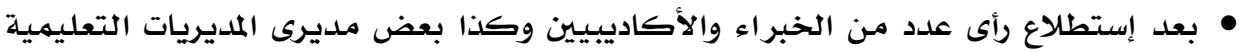

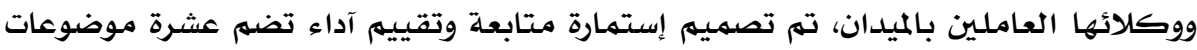




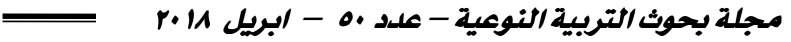

رئيسـة تغطى المهام الأساسية لمدير المديرية ووكيلها، وقد روعى فى تصميهم الإستهمارة أن تكون

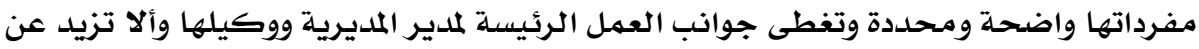

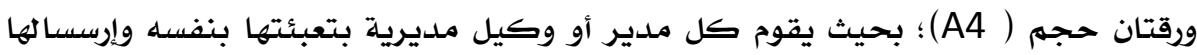

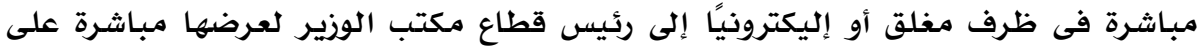

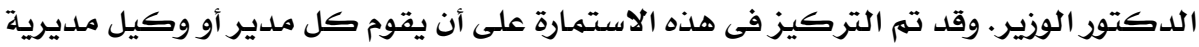

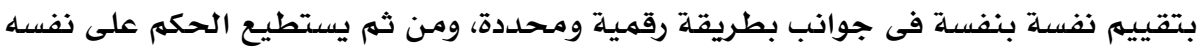

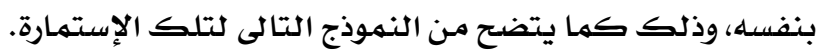

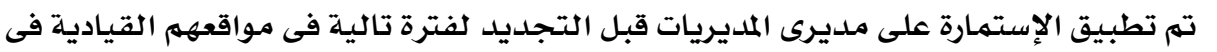

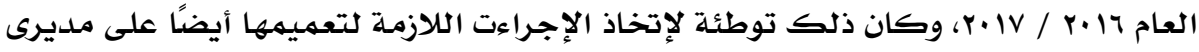

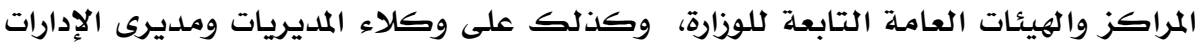

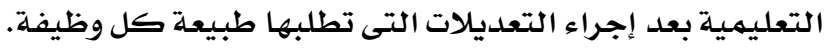

جدول (1)

إستمارة تقييم مديرى المديريات التعليمية ووكلائها

\begin{tabular}{|c|c|c|}
\hline الجهود المبذولة & بنود التقييي & $\hat{\imath}$ \\
\hline & • • • • • إنتظام الدراسة والإمتحانات : & 1 \\
\hline & 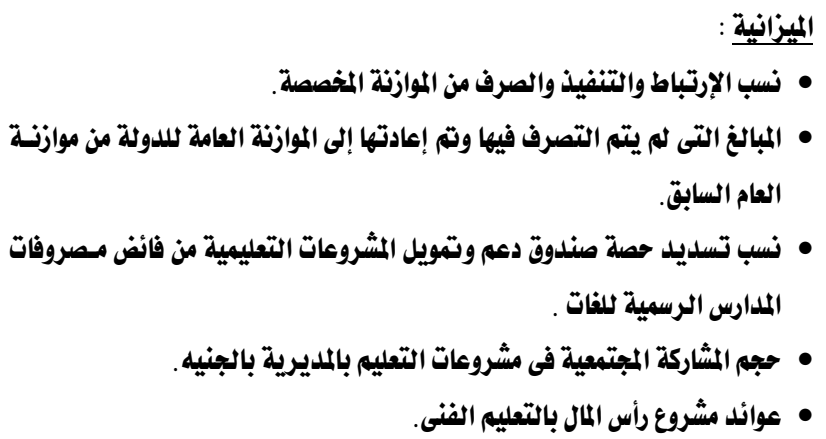 & $r$ \\
\hline & • • معدل تنفيذ الصيانات المستهلةفة. & $r$ \\
\hline & • الأشطة التربوية: $\quad$ علد البرامج التى تم تنفيذها خلال عام بالمدارس والإدارات بجميع المراحل وعـدد & $\xi$ \\
\hline
\end{tabular}




\begin{tabular}{|c|c|c|}
\hline & 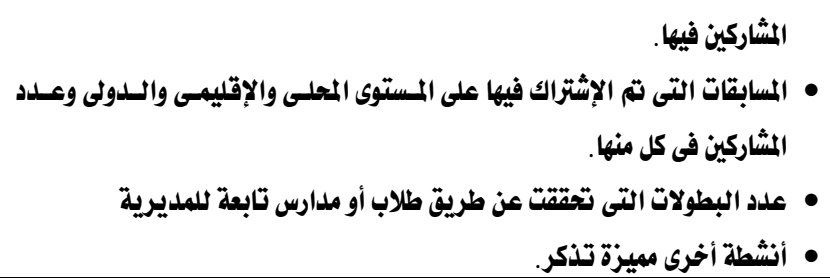 & \\
\hline & • التنسيبق: & 0 \\
\hline & 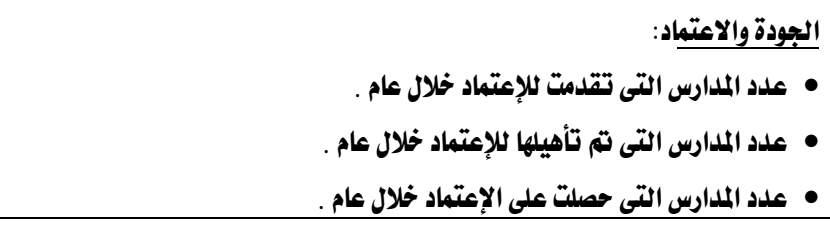 & 7 \\
\hline & 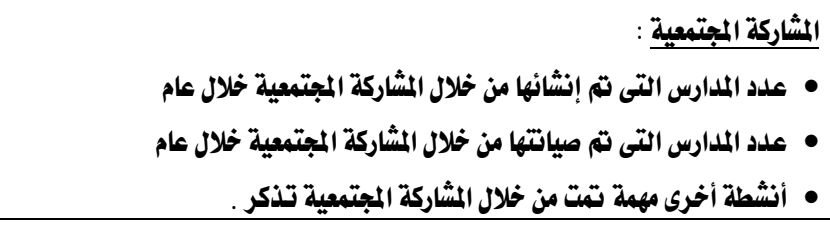 & v \\
\hline & 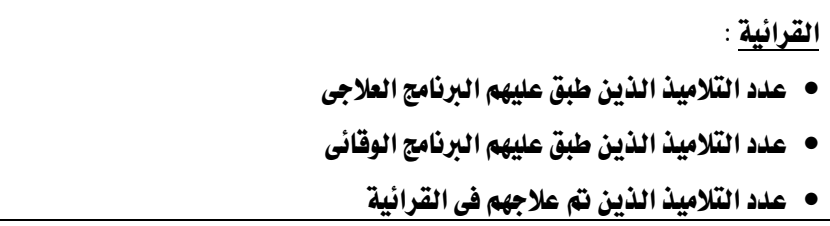 & $\wedge$ \\
\hline & •• • • عواجهة الفساد المالى والإدارى: & 9 \\
\hline يرسل منفصل فى ظرف مفلق السيد الوزير مباشرة & • رأى السيد المحافظ & 1. \\
\hline
\end{tabular}

• إصدار تعليمات محددة وقاطعة بتدوير المشاركة فى برامج التدريب والندوات والمؤتمرات

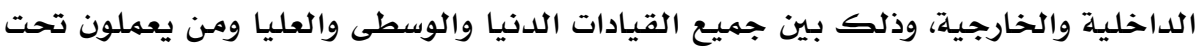

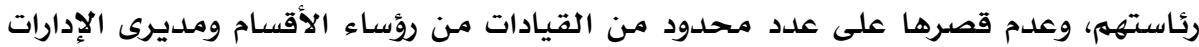

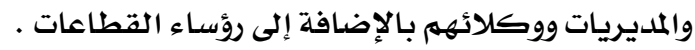


r. بالنسبة لإنخفاض مستوى الخدمات المقدمة بمكاتب خدمة المواطنين ومكاتب الإتصال السياسى بديوان عام

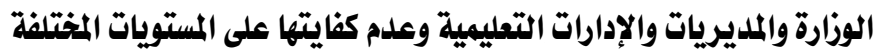

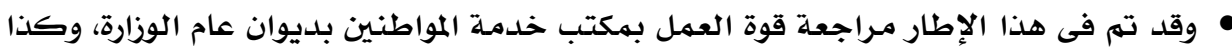

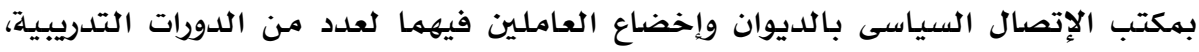

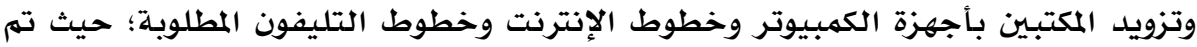

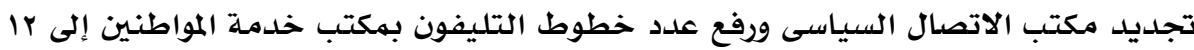

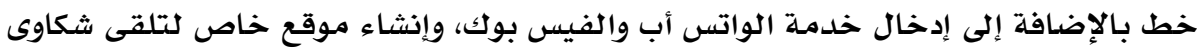

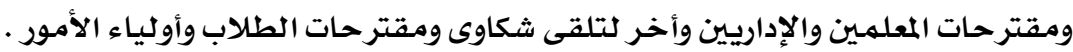

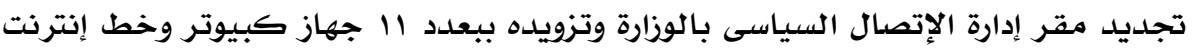

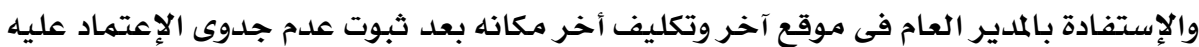

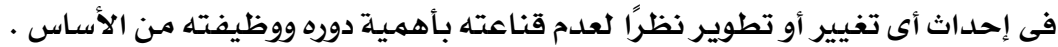

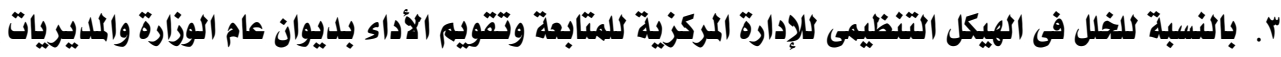
والإدارات التعليمية • يفتقد معظم العاملين بهذه الإارة للإستقرار الوظيفى نظرًا لأن معظمهم مدرسين منتدبين من المدارس. • معظم العاملين بهذه الإدارة غير ملمـين بطبيعة المهام المكلفين بأدائها من خلال هذه الوظيفة،

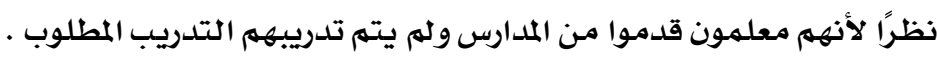

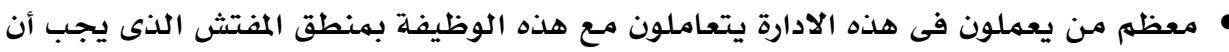

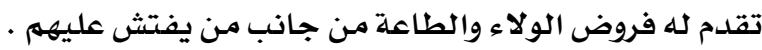

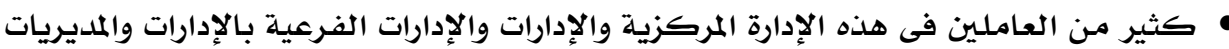

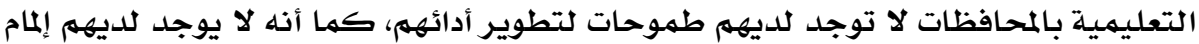

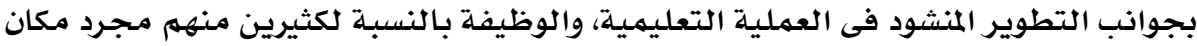

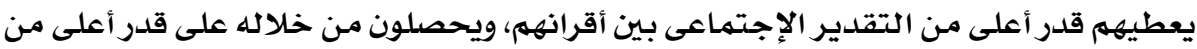

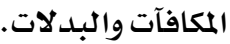

\section{وفى ضوء ما انتهى إليه تحليل الوضيع الراهن تم التوجيه بـالأتى:}

• مراجعة ملفات جميع العاملين بهلذه الإدارة والإدارات الفرعية بالمديريات التعليمية وإتخاذ قرار

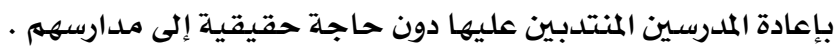

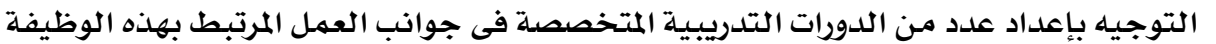

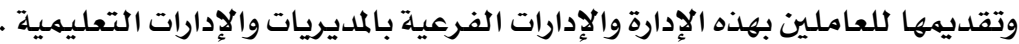

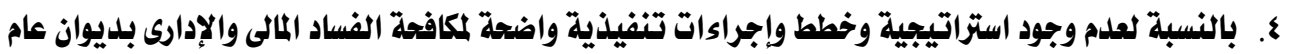
الوزارة والملديريات التعليمية ولمدية وفى هذا الصدد تم اتخاذ الإجراءات التالية: 


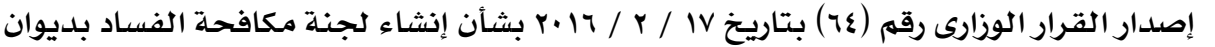

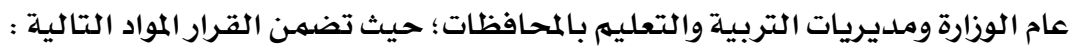

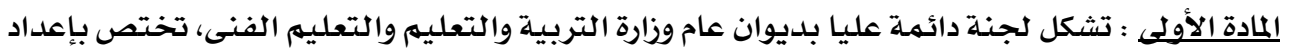

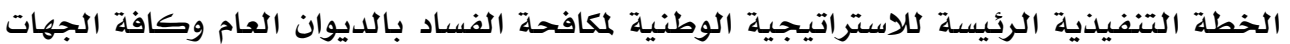

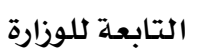

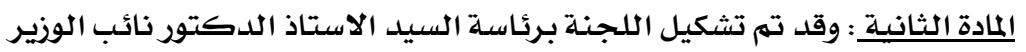

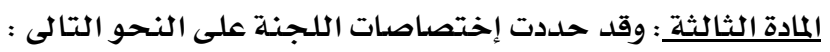

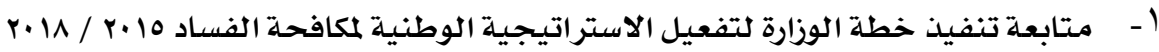

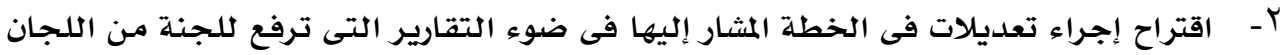

$$
\text { الفرعية . }
$$

"- - تكليف من ترى اللجنة تكليفه بمهام محددة، والتنسيق مـع الأجهزة والجهات المعنية لتحقيق

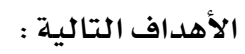

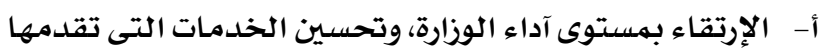

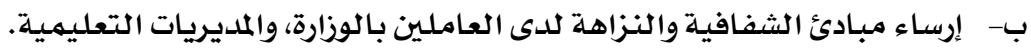

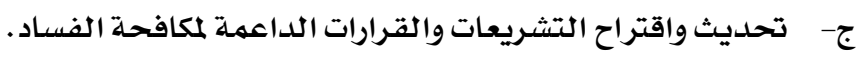

د- رفع مستوى الوعى الجماهيرى بخطورة الفساد وأهمية مكافحته، وبناء ثقة المواطنين فى الثى

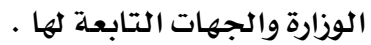

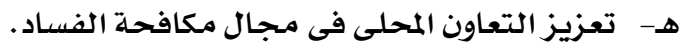

و- تعزيز التعاون الإقيمى والدولى فى مجال مكافحسة الفساد.

ز - المشاركة مـع منظمات المجتمـع المدنى فى مكافحة الفساد.

ع- - تقديم النصح والإرثاد للجان مكافحة الفساد الفرعية، بشأن إعداد الخططالتنفيذية الكلازمةلمكافحة الفساد.

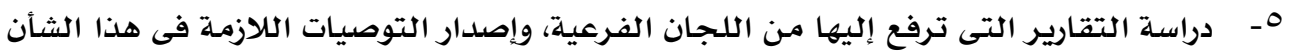

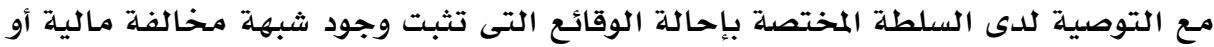

$$
\text { إدارية للتحقيق. }
$$

الممادة الرابعة : وقد تضمنت تشكيل لجان فرعية لمكافحـة الفساد بواقع لجنـة بديوان عام كل مديرية

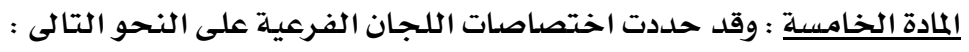

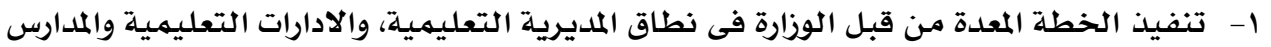

التابعة لها .

r- تكليف من ترى اللجنة تكليفه بمهام محددة، والتنسيق مع الأجهزة والجهات المعنية لتحقيق

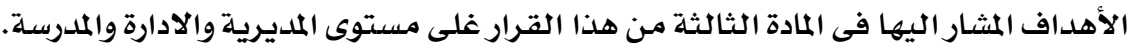


r- إعداد تقارير دورية عن مدى التقدم فى تنفيذ الخطة وعرضها على اللجنة المشار إليها فى المادة

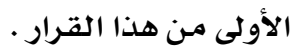

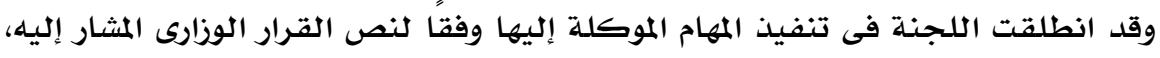

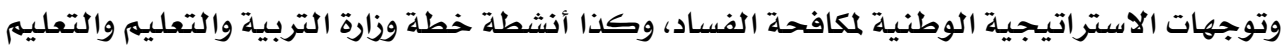

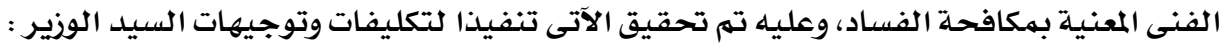
أ- الانتظام فى عقد اجتماعات اللجنة بمعدل مـرتين شهريًا تقريبًا.

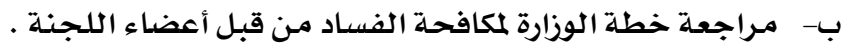

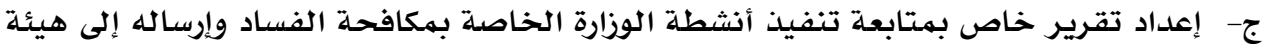

$$
\text { الرقابة الإدارية . }
$$

د- دراسة مدىى التزام بعض الإدارات التعليمية (وخاصدة فى محافظتى القاهره والجيزة) بأحكام

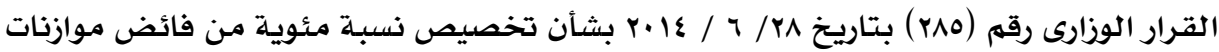

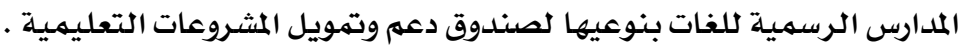

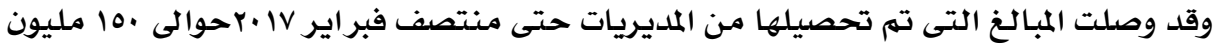

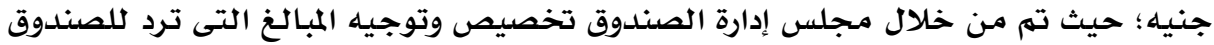

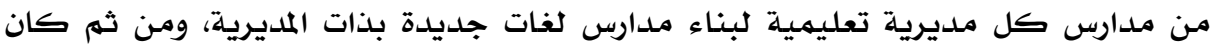

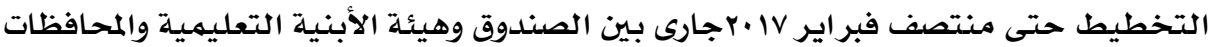

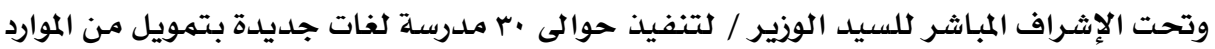

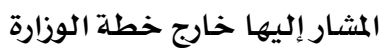

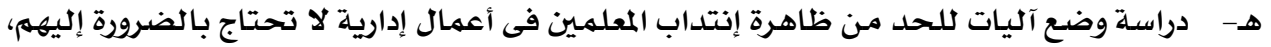

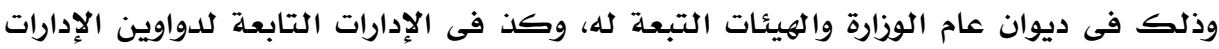

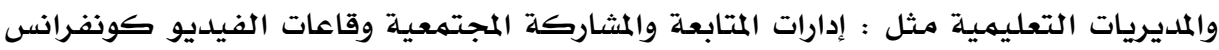

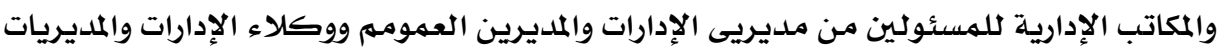

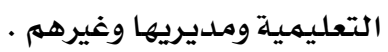

و- تشكيل لجنة لترشيد الإنفاق، ومتابعة الحد من إهدار المال العام، والإرتقاء بجودة تأليف

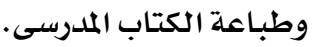

ز- تشكيل لجنه فنية من المتخصصدين بالجامعات والمؤسسات الإنتاجية لدراسة تعظيم الاستفادة

$$
\text { من مطبعـة شبرا . }
$$

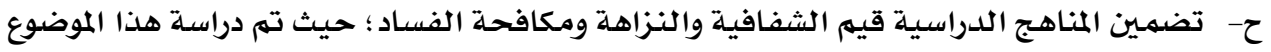
بالتعاون مـع قطاعى التعليه العام والفنى، وأساتذة المراكز البحثية التربوية التابعة للوزارة،

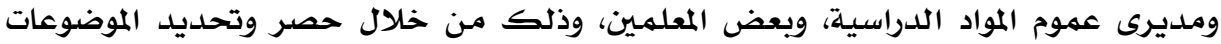

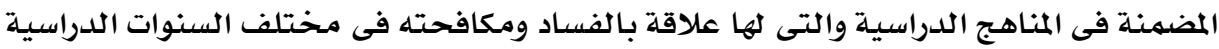

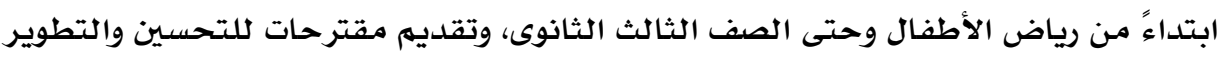


بما يساعد على توصيل الرسالة المستهدفة إلى الطلاب والمعلمين بشكل أفضل وأكثر عمقا

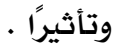

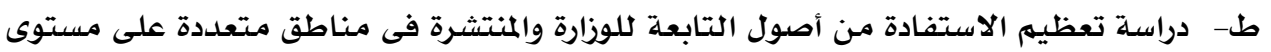

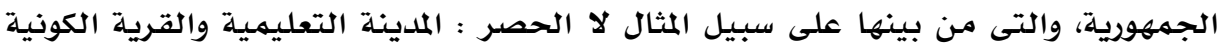

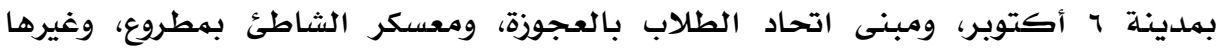

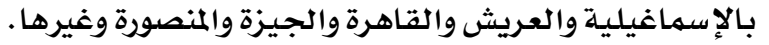

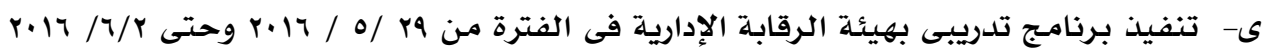

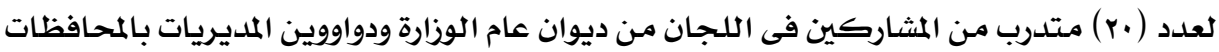

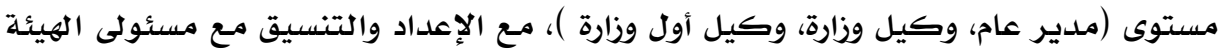

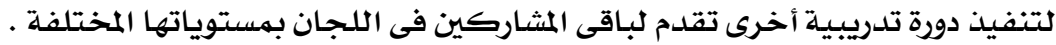

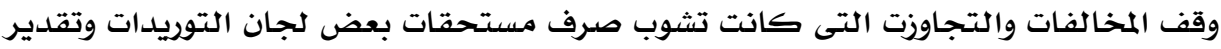

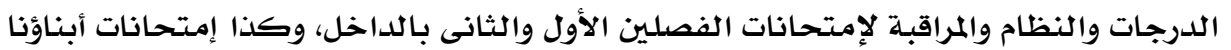

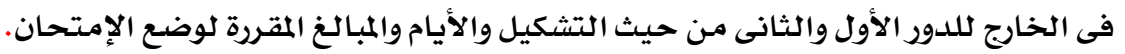

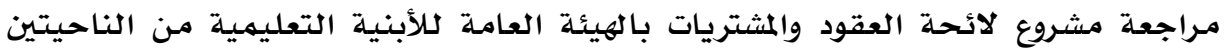

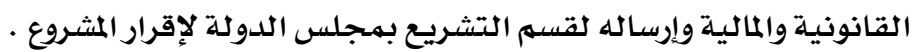

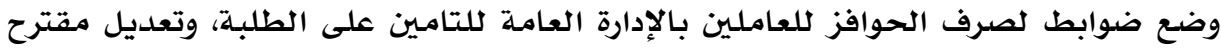

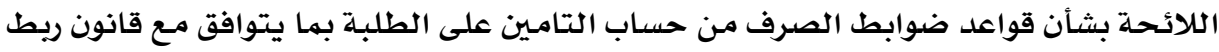

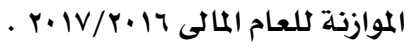

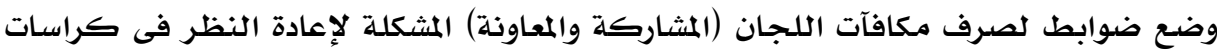

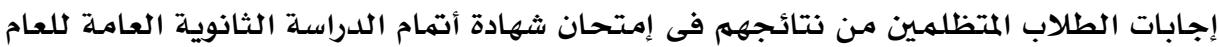

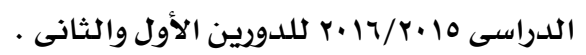

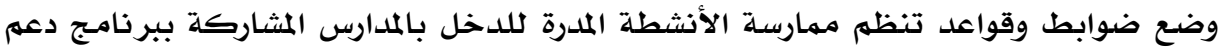

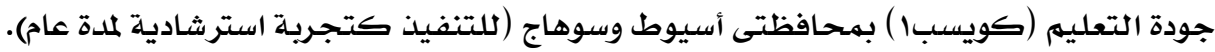

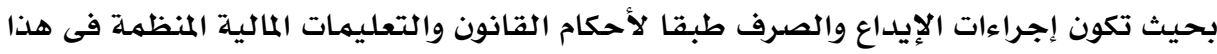

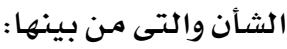

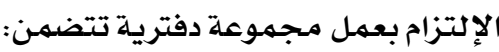

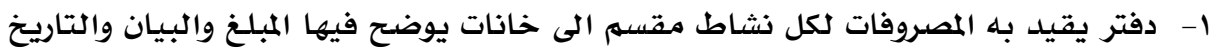

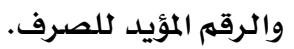
r- ب وفتر لقيد الإيرادات لكل نشاط على حدة.

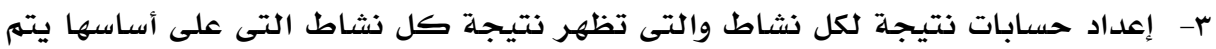

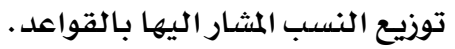
الإلتزام التام بعمل مجموعة مستنديه، لكل نشاط على حدة، وكذلك لأعمال الصيانة

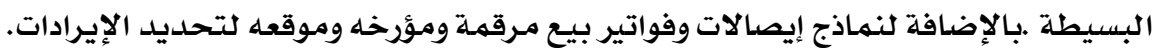




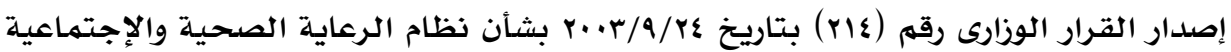

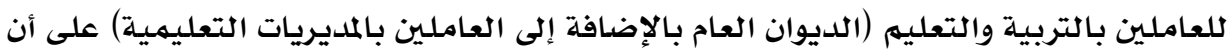

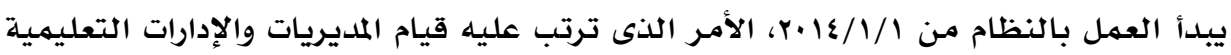

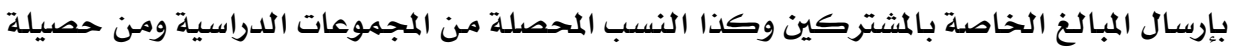

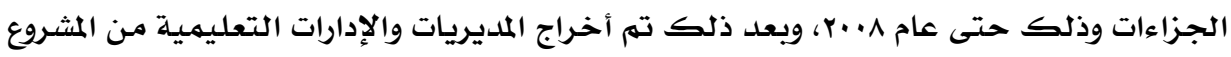

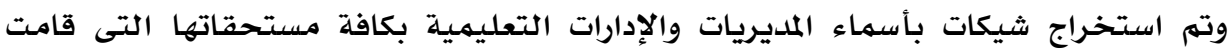

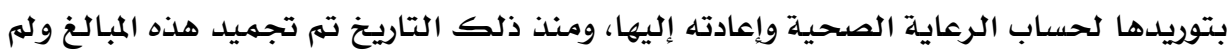

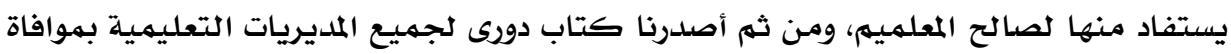

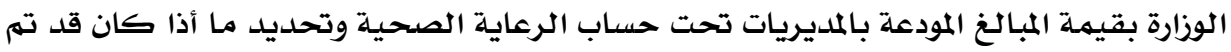

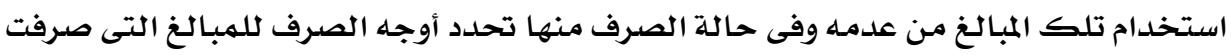

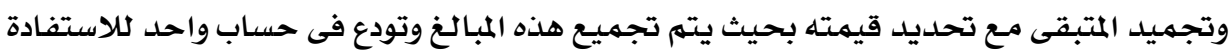

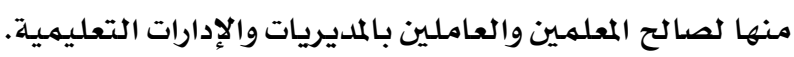

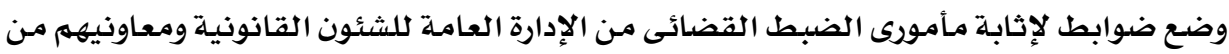

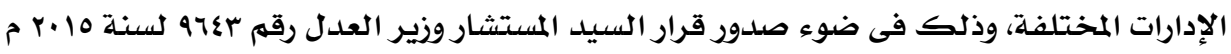

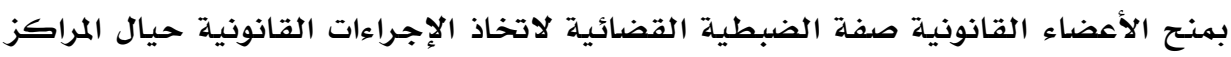

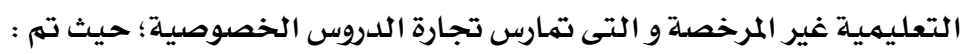

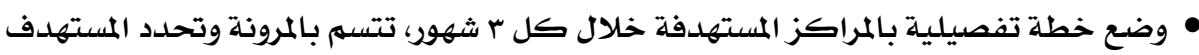
الذى يتمم الإثابة على ما يتم إنجازه منها.

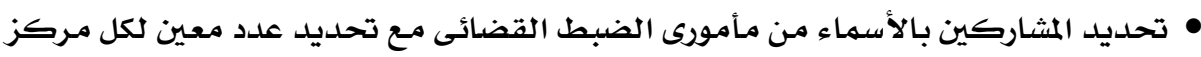

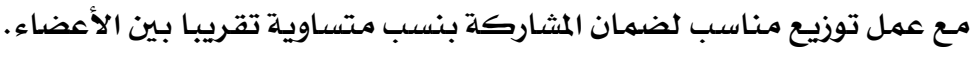

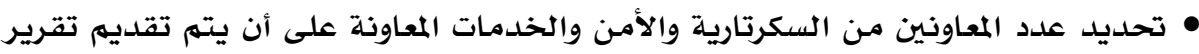

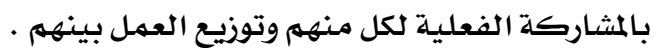

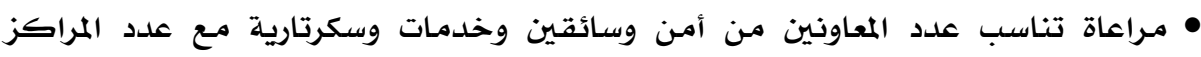

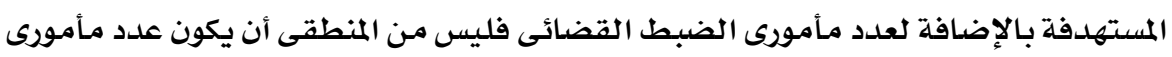

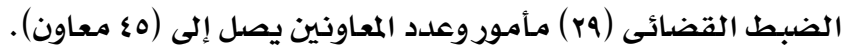

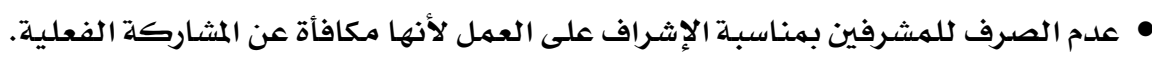

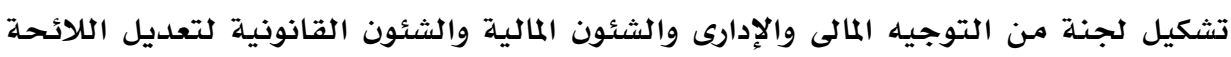

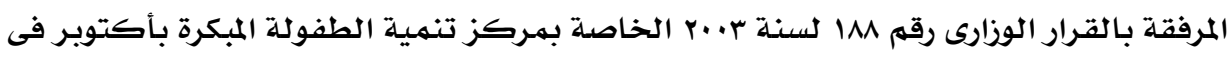

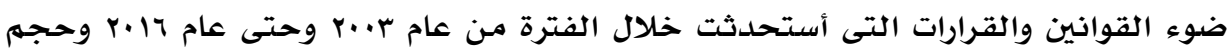
الأعمال التى يقوم بها المركز.

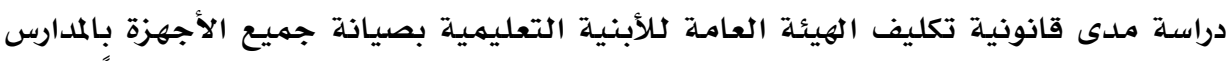

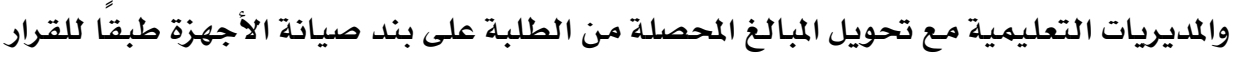

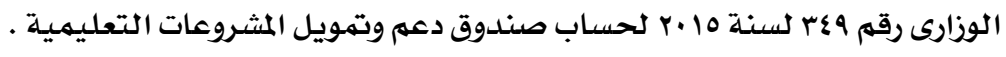


دراسة مدىى قانونية قيام إحدى الهيئات التابعة للوزارة بشراء قطع غيار أجهزة عن طريق مناقصدة

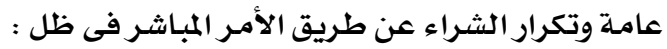

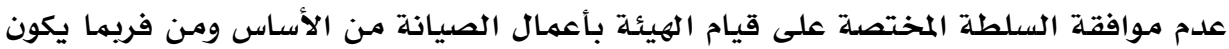
الشراء قد تم بدون وجود احتياجات حقيقية أو فعلية .

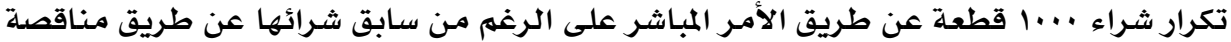
عامـه. شراء قطع M.B نظرًا لوجود بروسيسور DC2 داخل مخازن الهيئة، على الرغم من التطور

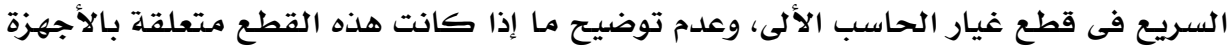

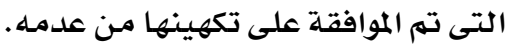
عدم الأمانة فى العرض على السلطة المختصلة مما تسبب فى إهدار المال العام؛ حيث تم الشراء

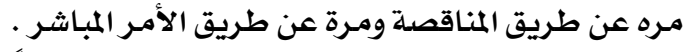

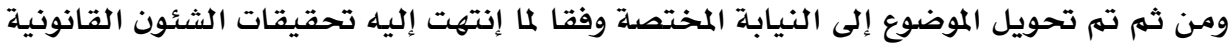

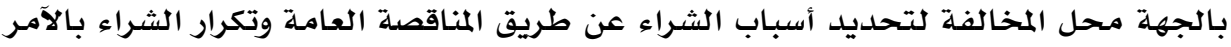

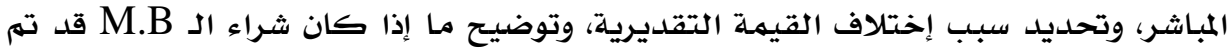

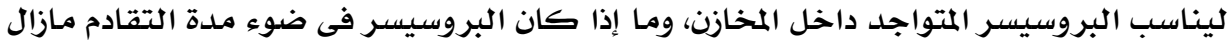

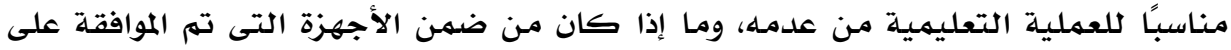

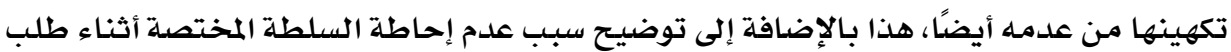

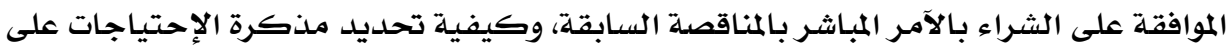

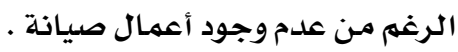
وضع ضوابط لصرف المبالغ المرحلة لحساب فحص ومراجعة كتب اللغات التى يتم تحصيلها

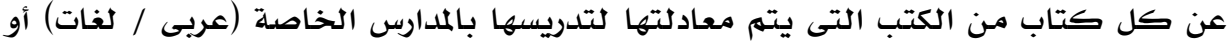

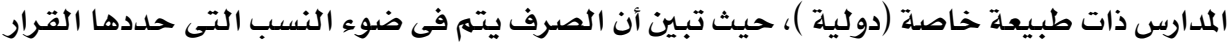

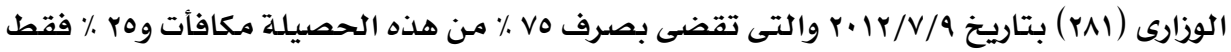
لمساب تنمية الموارد .

وقد شمل التعديل وضع قواعد بالنسبة للمدارس الخاصة والمراكز التعليمية، وكذلك

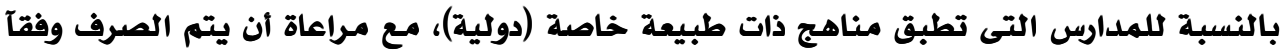
كلقواعد التالية :- باليه للمبل

أولا : بالنسبة للمدارس الخاصـة والمراكز التعليميـة (تصرف بحـد أقصى الحصيلة وفقـآ للنسب :

\section{التتالية): بالنة:}

نسبة هب٪ من الحصيلة لمستشارى المواد الدراسية المختصين بالفحص الفنى الحئ نسبة هץ٪ من الحصيلة للعاملين بالإدارة العامـة للتعليم الخاص .

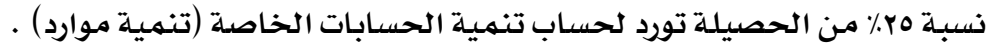

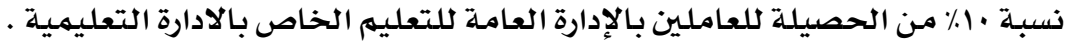




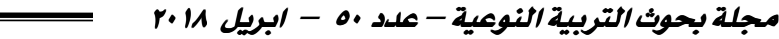

نسبـة • ا٪ مـن الحـصيلة للعـاملين بـالإدارة العامـة للتعلـيهم الخـاص بالمديريــة التعليميسة

المختصة.

نسبة ب٪ من الحصيلة للعاملين المعاونين من مكتب الوزير .

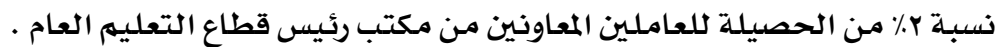

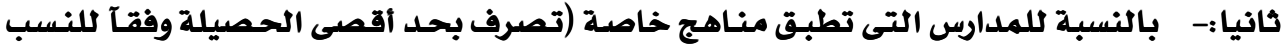

التالية ):

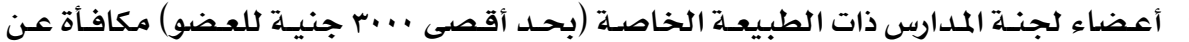

الجلسة.

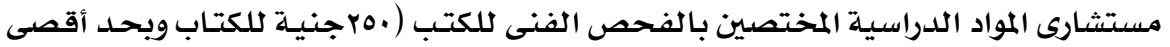

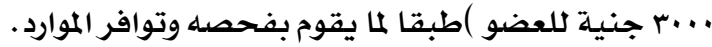

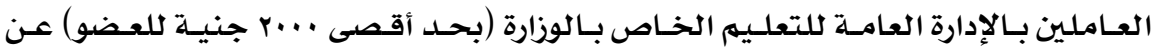

الجلسة . العاملان.

القائمـين بفحص ملفات المدارس التى يتهم عرضها على لجنـة المدارس ذات الطبيعـة الخاصسة

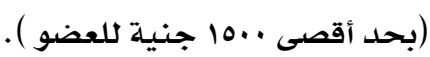

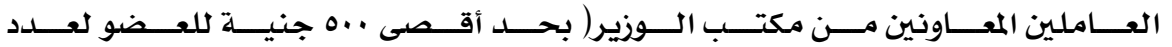

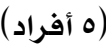

العـاملين المعـاونين بمكتب رئـيس الإدارة المركزيـة المختصـ (ثانوى - خـاص رسهى لغـات )، ومكتب رئيس قطاع التعليه العام (بحد أقصى ..0 جنية للعضو لعدد (ه أفراد).

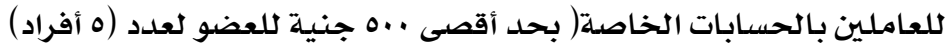

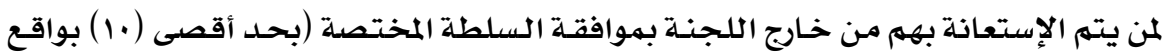
V0.

تـورد بـاقى الحسـيلة السشهرية التـى تم الإثابـة عليهـا مناصـفة بــين حسـاب تنميسة المـوارد وصندوق دعم وتمويل المثروعات التعليميلة.

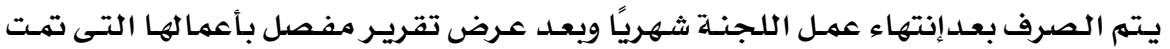
وموافقة السلطة المختصة عليه .

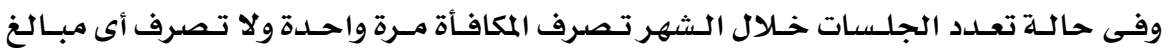
إضافية .

و ولا يجوز تكرار الصرف من نفس الحصائل التى تم الإثابة عليها خلال الفترة السابقة .

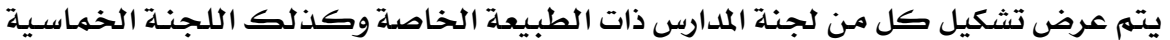

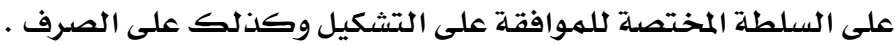

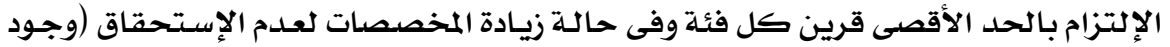

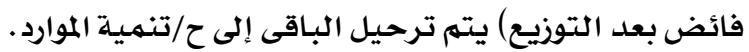


يتم الصرف بناء على قائمة الأعمال المعتمدة من الإدارة المختصة موضحآ بها المواد التى تم

معادلتها .

• لا يجوز الصرف لأى من المشاركين فى حالة حصوله من الوزارة على مكافأة مقطوعة .

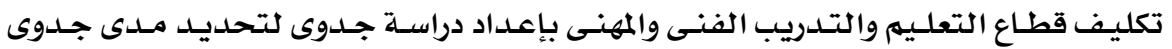

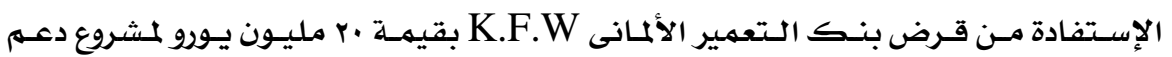

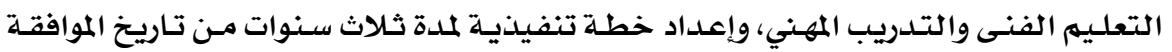

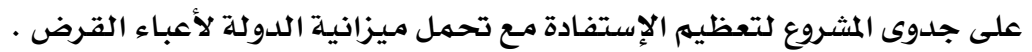

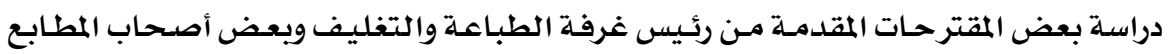

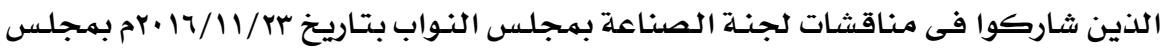

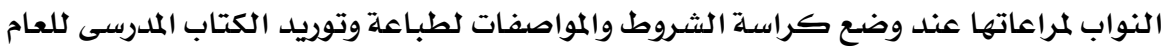

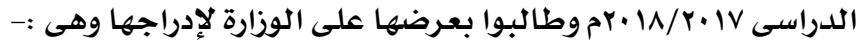

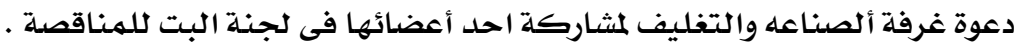

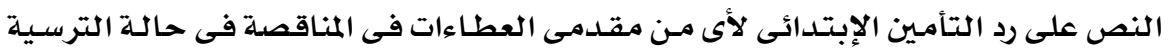

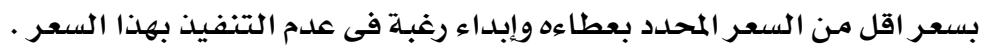

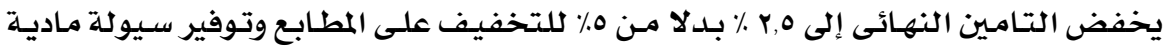
لها. وبعد الدراسة المالدية والقانونية المستفيضة تم رفض هذه المقتر حات نظرًا لعدم إتفاقها مـع أحكام القانون أو طبيعة المناقصة .

وضـع ضـوابط لصـرف مكافأة لجـان تهيئسة الكتب الدراسـية المقـررة لمدارس النـور للمكفـوفين

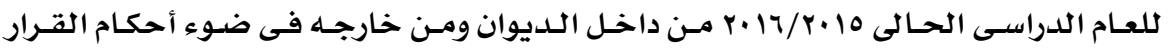

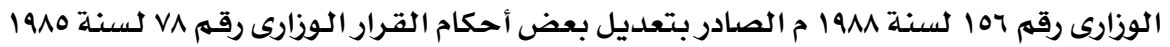

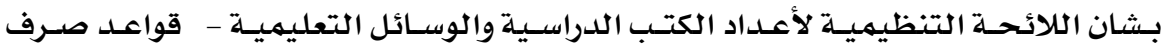
مكافآت التعديل.

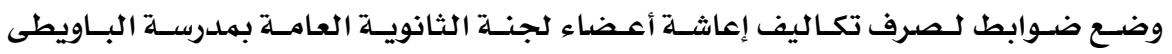

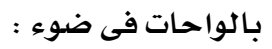

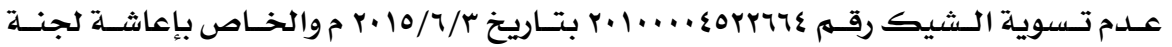

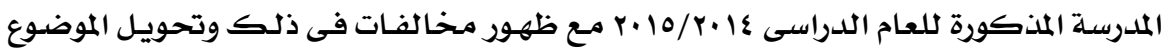
للنيابـة.

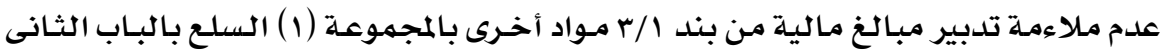

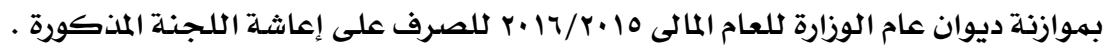

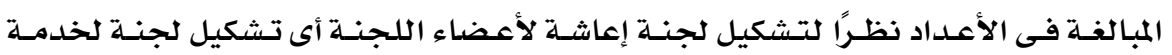

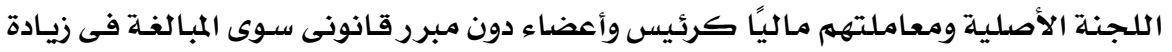
الأعضاء للاستفادة ماليًا . الاصلية ومعاملتهاء 
وجـود كثثير مـن الكنترولات على مستوى الجمهوريـة تقع فى منـاطق نائيـة وله يطلب مـن

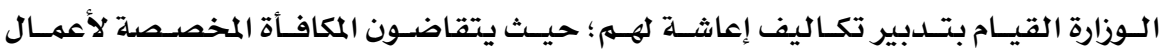
الإمتحانات فى المناطق النائية نظير أعمالهم.

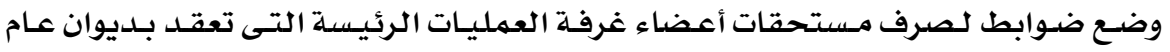

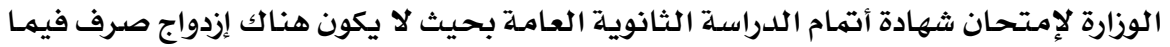

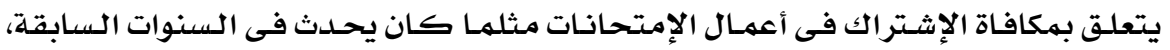

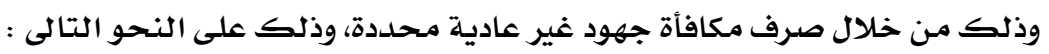

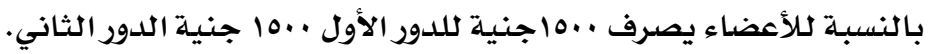

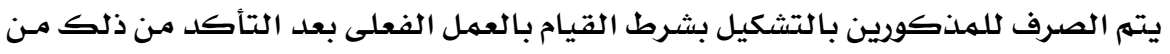

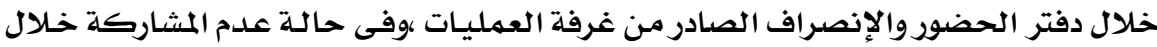

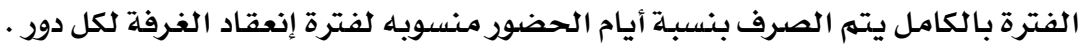

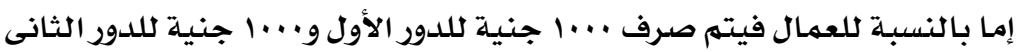

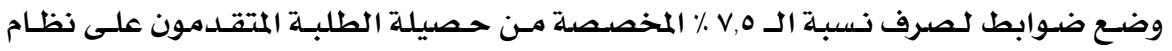

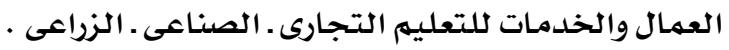

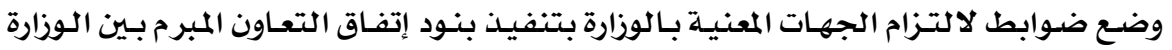

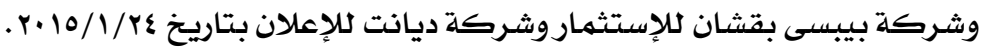

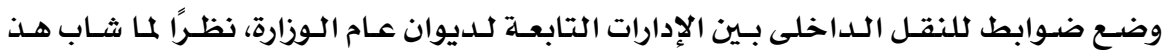

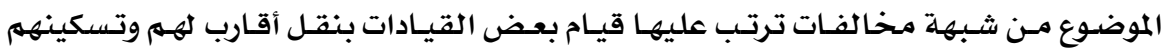

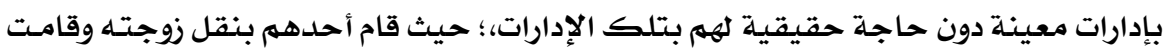

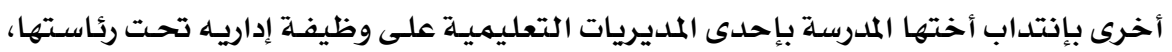

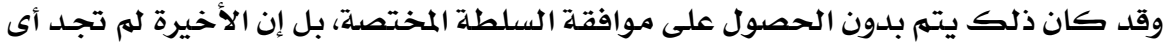

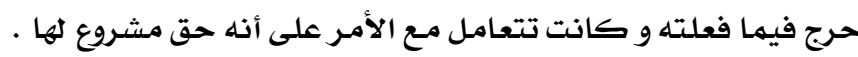

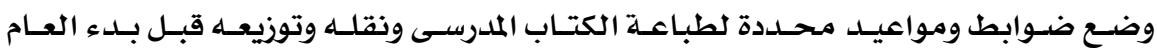

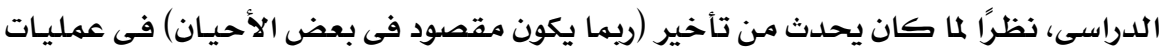

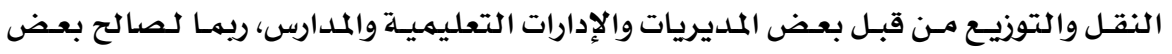

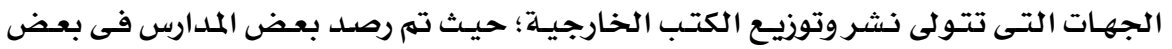

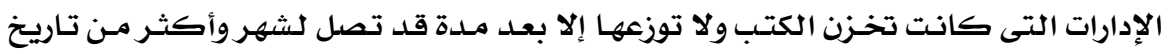

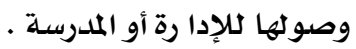

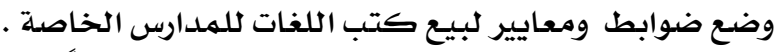

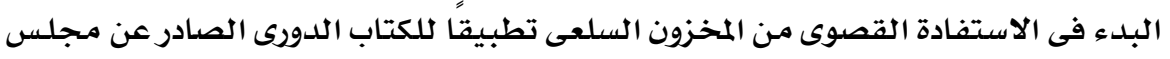

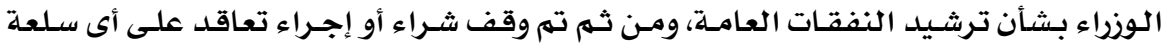

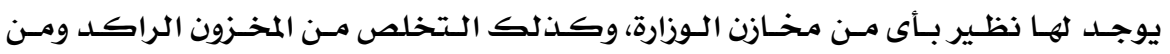

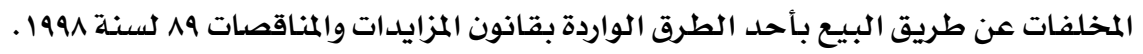


إصدار تعليمات بالبدء فى تطبيق تجرية الشراء المركزى؛ حيث تم البدء فى اتخاذ اجـراءات

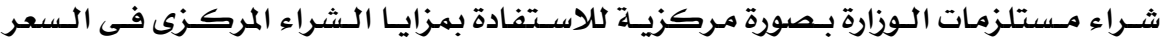

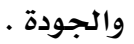

• البـدء في ترشـيد النفقـات بـديوان عـام الوزارة للوصـول إلى النسبـة التى صـدر بهـا قـرار مـن مجلس الوزراء من تليفونات ومياه وإنارة وإجراء الصيانة المطلوبة لضبط النفقات .

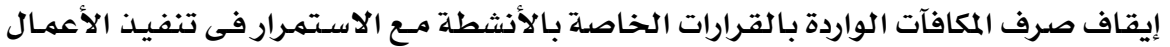

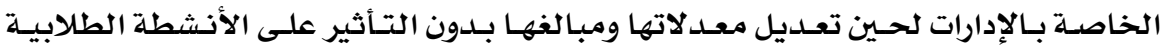
المختلفة.

هـ بالنسبة للخلل الكبير فى توزيع المعلمين بين المدارس داخل كل إدارة، وبين الإدارات، وبين الملديريات، وإتتلاب علد كبير منهم على وظائف إدارية

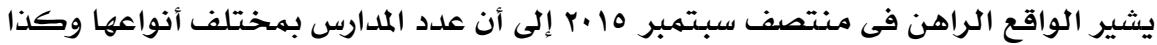

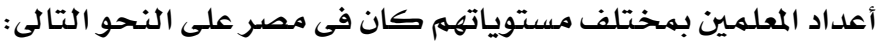

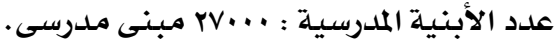

$$
\begin{aligned}
& \text { عدد المدارس: ... . . مه مدرسة. }
\end{aligned}
$$

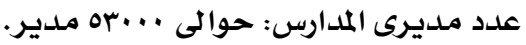

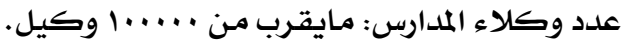

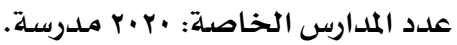

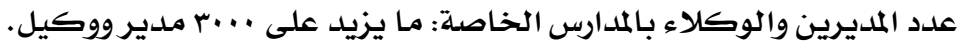

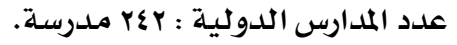

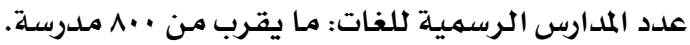

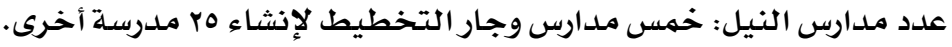

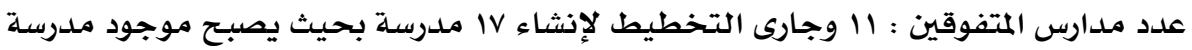
بكل محافظة .

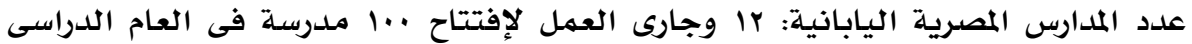
$r+1 \Lambda-r+1 V$

$$
\begin{aligned}
& \text { عدد الفصول الدراسية: ... .0 ع فصل تقريبًا. }
\end{aligned}
$$

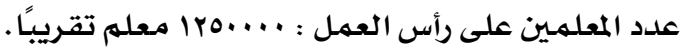

$$
\begin{aligned}
& \text { عدد الإداريين والأخصائيين : ....0.0. عب تقريبًا. }
\end{aligned}
$$

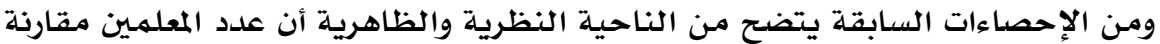

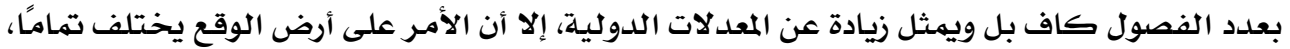

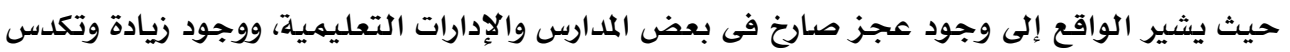

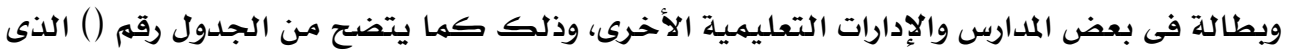

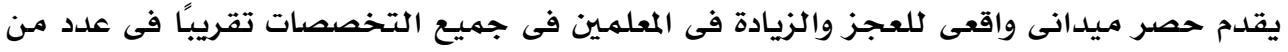




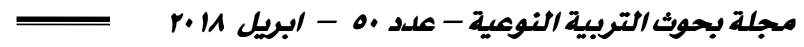

المديريات التعليمية، تشمل (المنيا، والقليوبية، والثرقية، وقنا، وسوهاج، والإسماعيلية، والفيوم )،

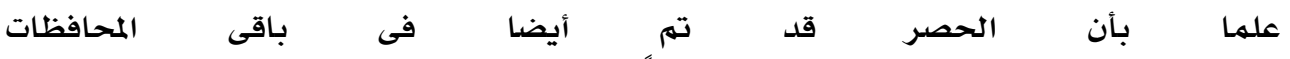

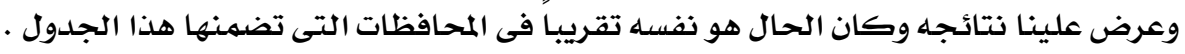

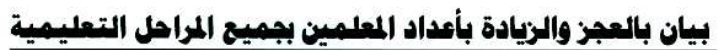

\begin{tabular}{|c|c|c|c|c|c|c|c|c|}
\hline الفيوم & 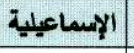 & تصواج & تن & الثشرقية & القليوبية & المنيا & عجز/زيادة & العادة \\
\hline 79. & ir & $r r$ & - & AqY & 94 & rus & عجز & \multirow{2}{*}{ اللغة العربية } \\
\hline rI & ra & $\varepsilon V$ & - & INQY & 1.74 & $r \Lambda . r$ & زيادة & \\
\hline $11 \varepsilon$ & 11 & - & 19. & $I V A$ & $r \varepsilon r$ & YYV & عجز & \multirow{2}{*}{ للفة الإنجليزية } \\
\hline ra & - & 9TV & rrq & $\mathrm{rq.}$ & $\Lambda \leqslant \wedge$ & IAvV & زيادة & \\
\hline - & 11 & - & - & ir & - & - & عجز & \multirow{2}{*}{ اللغة الالمانية } \\
\hline- & 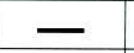 & - & - & - & - & - & زيادة & \\
\hline- & $\wedge$ & - & $\varepsilon V$ & 19 & - & - & عجز & \multirow{2}{*}{ اللغة الفرنسية } \\
\hline$\longrightarrow$ & - & 1.1 & $\{\Lambda$ & וזי & $r \cdot r$ & - & زيادة & \\
\hline $1 \% 0$ & - & 17 & $r \varepsilon$ & $M$ & 171 & ir. & عجز & \multirow{2}{*}{ العلوم } \\
\hline$V_{7}$ & $r \cdot \varepsilon$ & - & Irv & vir & $7 \times 9$ & 110 & زيادة & \\
\hline$r \wedge$ & - & iv. & \&1 & - & 174 & $|r|$ & عجز & \multirow{2}{*}{ الاجتماعية } \\
\hline$r \wedge$ & $\longrightarrow$ & 114 & \&70 & - & $\varepsilon \pi$ & rAo & زيادة & \\
\hline- & Vr & $1.7 r$ & NOV & 740 & $71 \%$ & rYs & عجز & \multirow{2}{*}{ الرياضيات } \\
\hline$v \cdot r$ & 9. & - & YY & Vor & qua & $1 \leqslant 9$ & زيادة & \\
\hline - & - & - & - & $r$ & ra & Pr & عجز & \multirow{2}{*}{ الكيمياء } \\
\hline - & $r \varepsilon$ & - & - & YYY & 07 & $\wedge$ & زيادة & \\
\hline - & - & - & - & $0 \wedge$ & ra & $r$. & عجز & \multirow{2}{*}{ الفيزياء } \\
\hline - & ro & - & - & $11 \%$ & \&0 & ro & زيادة & \\
\hline - & $\longrightarrow$ & - & - & $\varepsilon$ & $1 \%$ & PY & عجز & \multirow{2}{*}{ الأحياء } \\
\hline - & $r v$ & - & - & $r \cdot \varepsilon$ & Vr & - & زيادة & \\
\hline- & - & $\varepsilon \leqslant r$ & $1 r \leqslant r$ & - & - & $9 V$ & عجز & \multirow{2}{*}{ تربية رياضية } \\
\hline VI & - & 11 & - & - & - & ir. & زيادة & \\
\hline - & - & - & - & - & - & $v \leqslant 9$ & عجز & \multirow{2}{*}{ تربية فنية } \\
\hline$\longrightarrow$ & - & - & - & - & - & $v \leqslant 1$ & زيادة & \\
\hline - & ะ94 & - & - & Try & - & $\leqslant 99$ & عجز & \multirow{2}{*}{ معلم الفصل } \\
\hline - & 00 & - & $\longrightarrow$ & ryar & minr & TAY & زيادة & \\
\hline- & - & - & - & - & YMI & - & عجز & \multirow{2}{*}{ الاجتماعية } \\
\hline$\longrightarrow$ & 109 & - & - & - & 11.9 & $901 \varepsilon$ & زيادة & \\
\hline
\end{tabular}

الجدول صادر عن إدارة التنسيق بديوان عام الوزارة 
وتجدر الإثـارة هنا أيضًت إلى هروب عدد كبير من المدرسين من خلال الندب أو النقل على وظائف

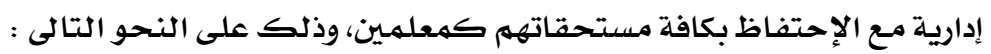

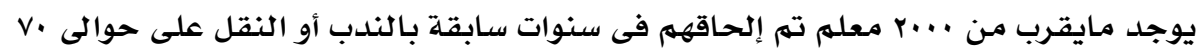

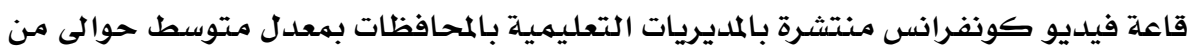

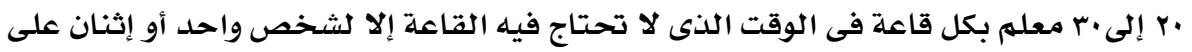

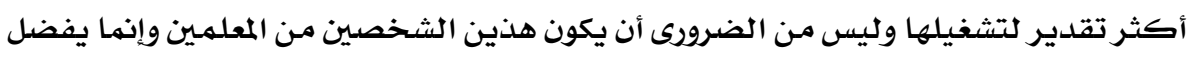

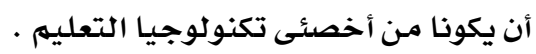

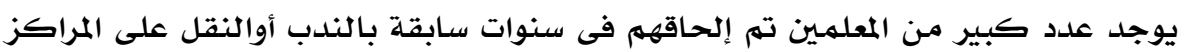

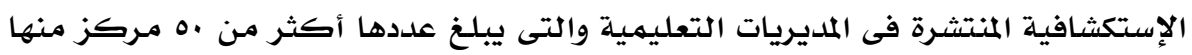

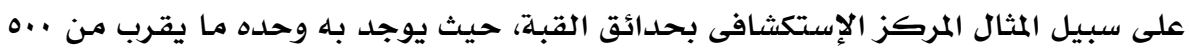

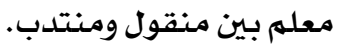

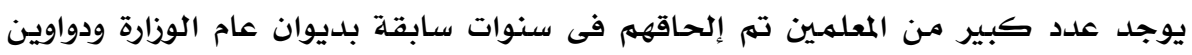

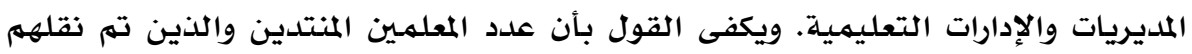

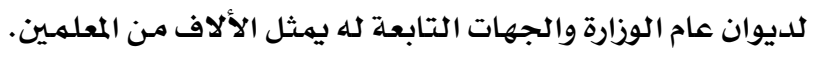

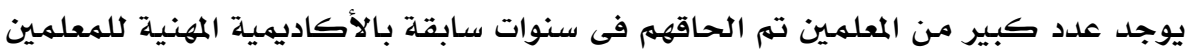
ومراكز التدريب المنتشرة بـالمحافظات.

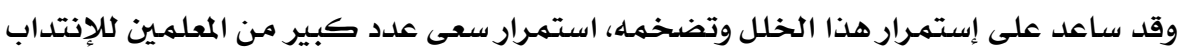

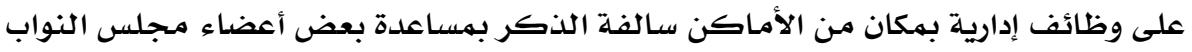

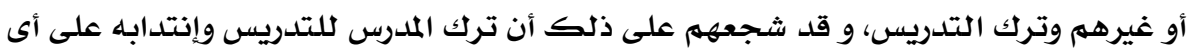

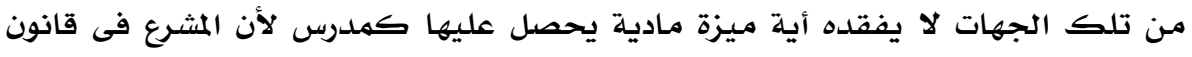

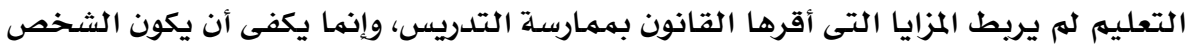

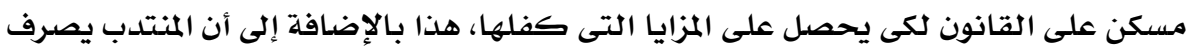

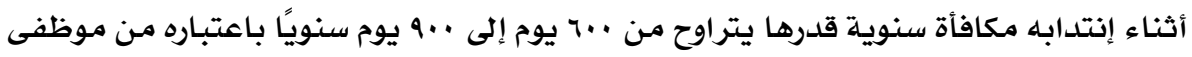

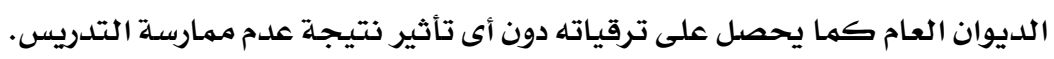

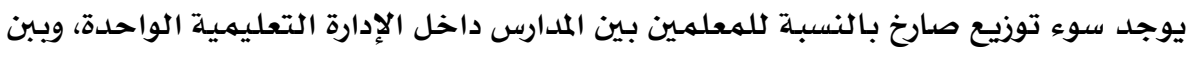

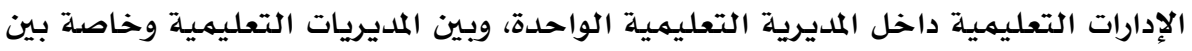

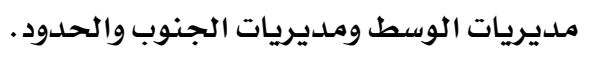

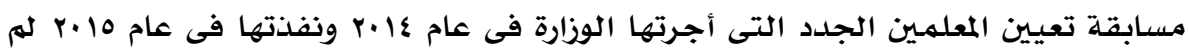

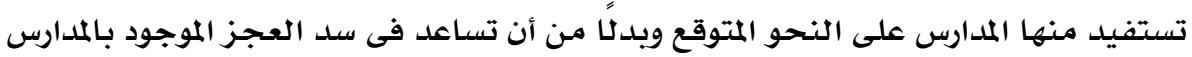

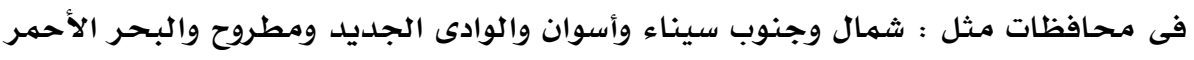

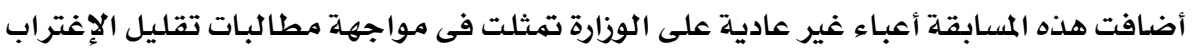

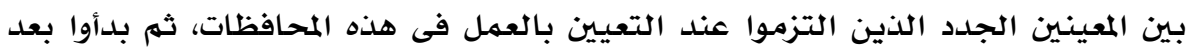

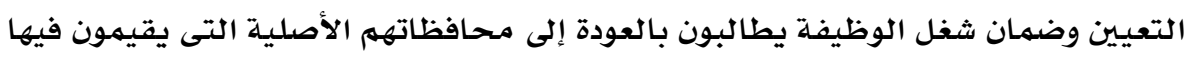


يساندهم فى ذلك بعض أعضاء مجلس النواب وبعض الإعلاميين والصحفيين دون النظر

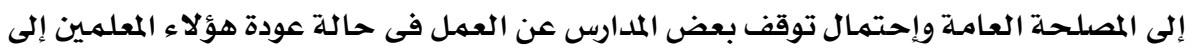

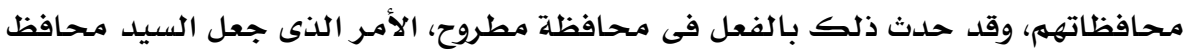

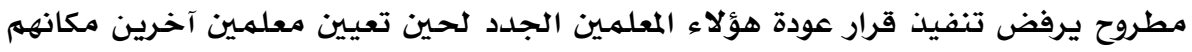

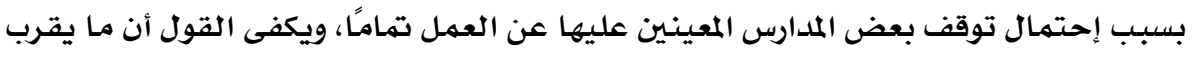

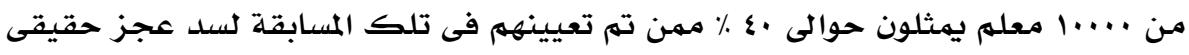

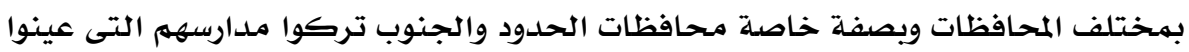

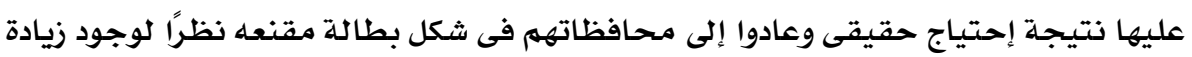

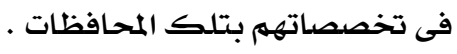

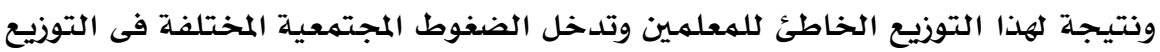

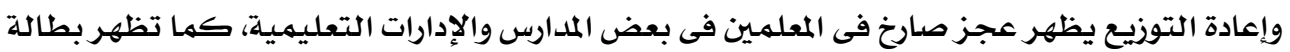

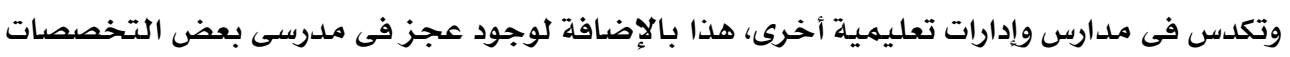

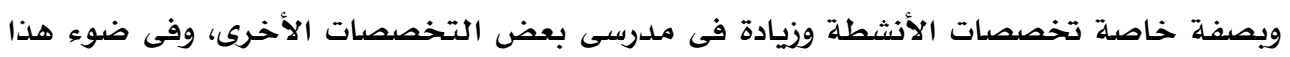

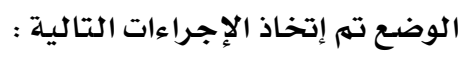

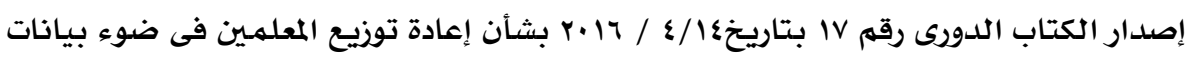

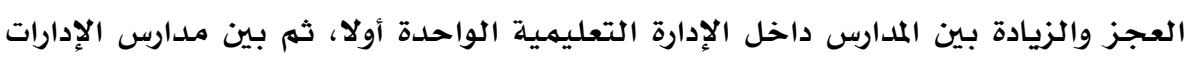

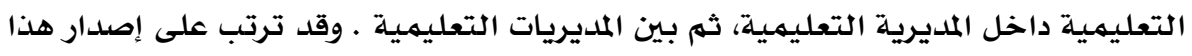

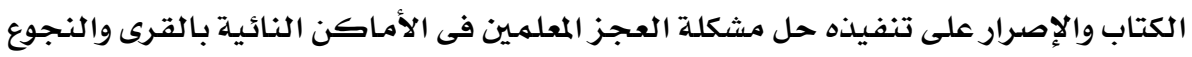

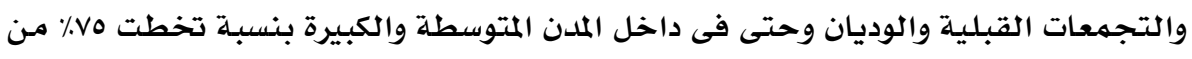

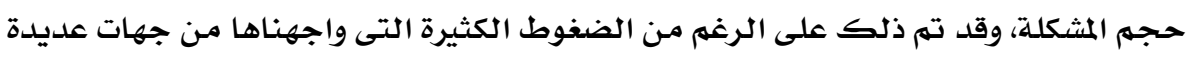

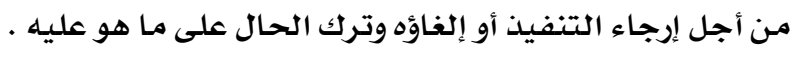
وقد تضمن هذا الكتاب المواد التالية :

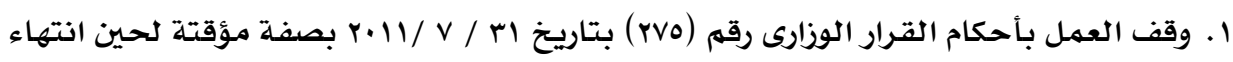

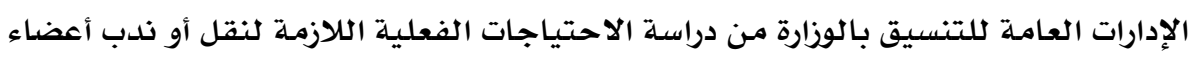
هيئة التعليهم الإدات التهاذ r. اتخاذ كافة الاجراءات الدلازمة لإعادة توزيع أعضاء هيئة التعليم داخل مدارس الإدارة

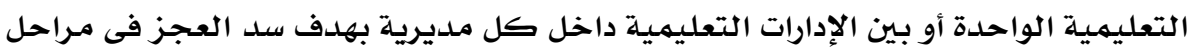

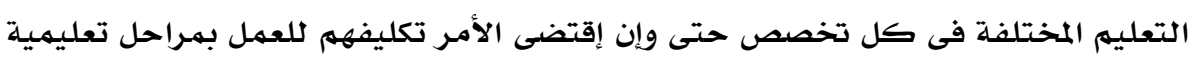

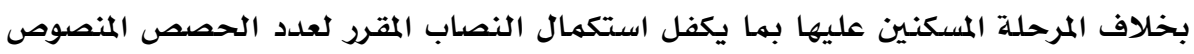

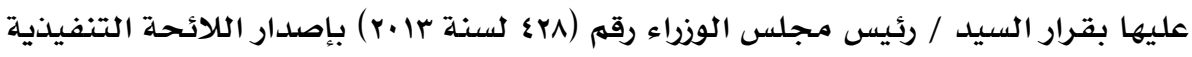

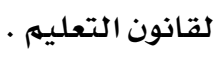

r. تشكيل لجنة بكل إدارة تعليمية وأخرى بكل مديرية تعليمية، وذلك على النحو التالى : 
أ- لجنة بكل إدارة تعليمية برئاسة مدير الإدارة التعليمية وعضوية كل من :

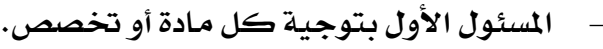

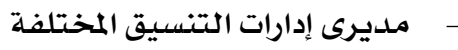

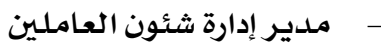

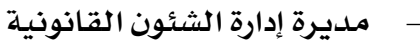

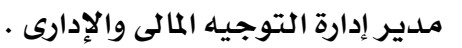

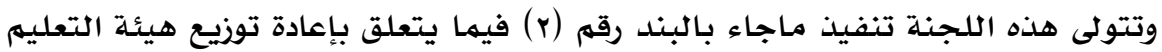

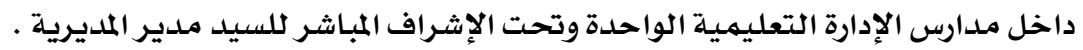

ب- لجنة بكل مديرية تعليمية برئاسة مدير المديرية وعضوية كل من :

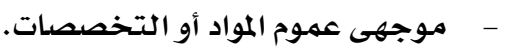

$$
\begin{aligned}
& \text { - مديرى التناسيق المختلفة. }
\end{aligned}
$$

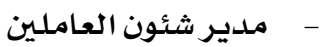

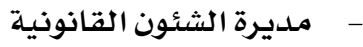

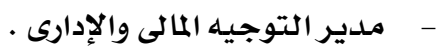

وتتولى هذه اللجنة تنفيذ ماجاء بالبند رقمم (r) فيما يتعلق بإعادة توزيع هيئة التعليم بين

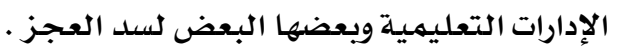

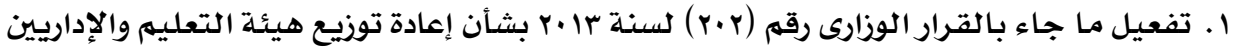

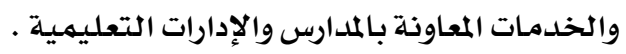

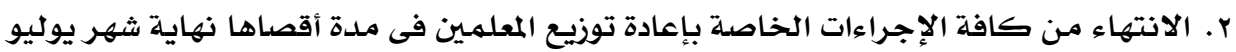

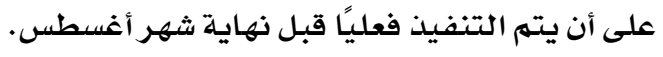

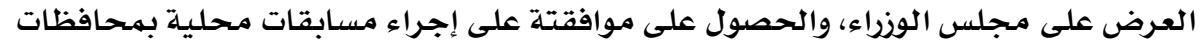

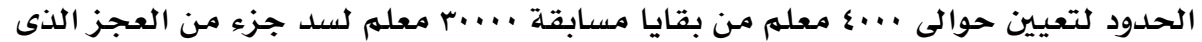

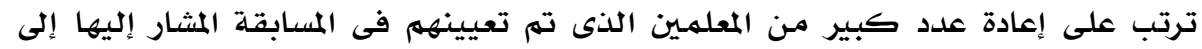
محافظاتهم نتيجـة الضغوط المجتمعية .

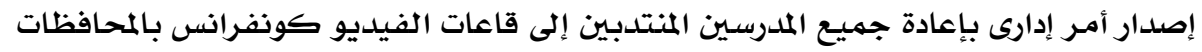

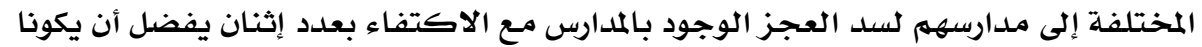

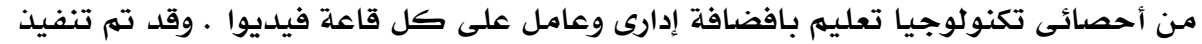
القرار على الرغم الإعتراضات والضغوط الكثيرة التى واجهناها فى سبيل التيل التأجيل أو الإرجاء.

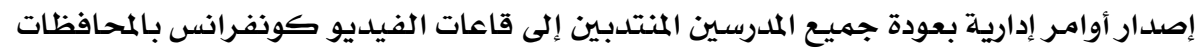

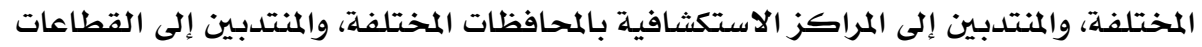

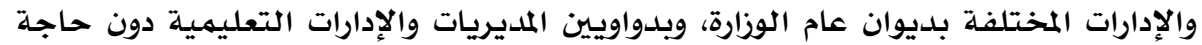

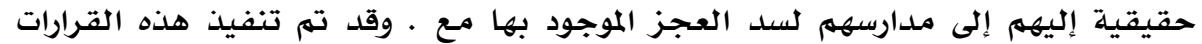

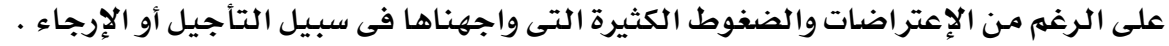


ז- بالنسبة لعدم الإستفلال الأمثل لأصول وممتلكات الوزارة وعلدم ترشيد الاستهلاك وزيادة الإنفاق

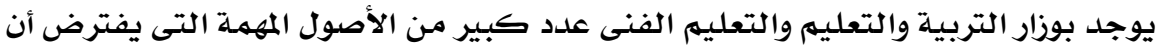
تدار بطرق غير بيرقراطية وغير تقليدية وبفكر غير فكر موظفى الحكومـة كى تدر دخلا معقولا

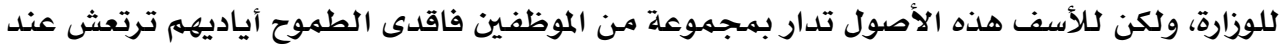

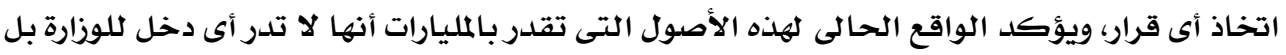

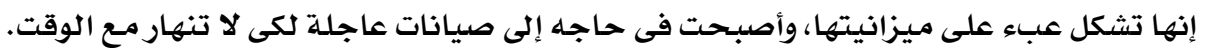
وفى ضوء ذلك تم تشكل لجنة من القيادات ذات العلاقة بالوزارة قامت بحصر أصول

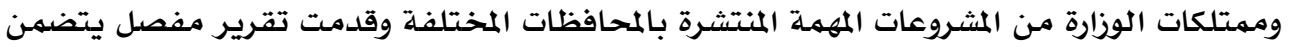

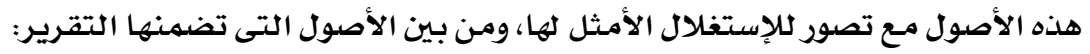
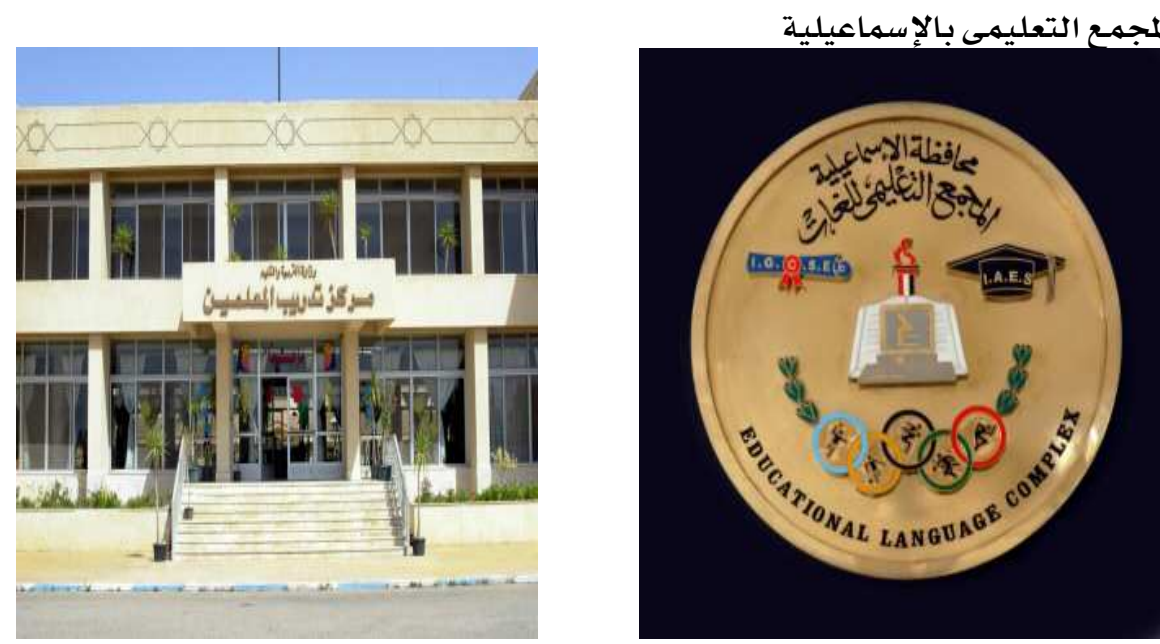

$$
\begin{aligned}
& \text { • المدينة التعليمية ب خ أكتور (جوهرة الصحراء ) . }
\end{aligned}
$$

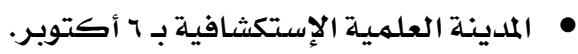

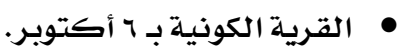

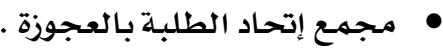

$$
\begin{aligned}
& \text { • مركز أعداد القيادات التربوية وفروعه بالمحافظات. }
\end{aligned}
$$

$$
\text { • متتحف التعليهم ومكتبـة الوثائق بالوزارة. }
$$

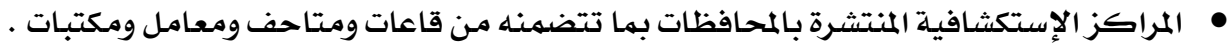

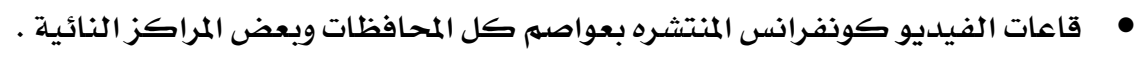

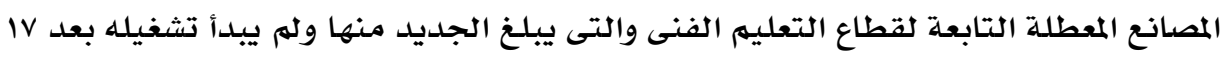

مصنح

وفى ضوء هذا التقرير تم إتخاذ الإجراءات التالية : 
• تم الكتابة لوزارتى التخطيط والإصلاح الإدارى والإستثمار للمساعدة فى طرح بعض هذه

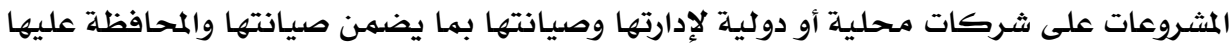

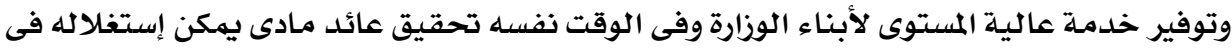

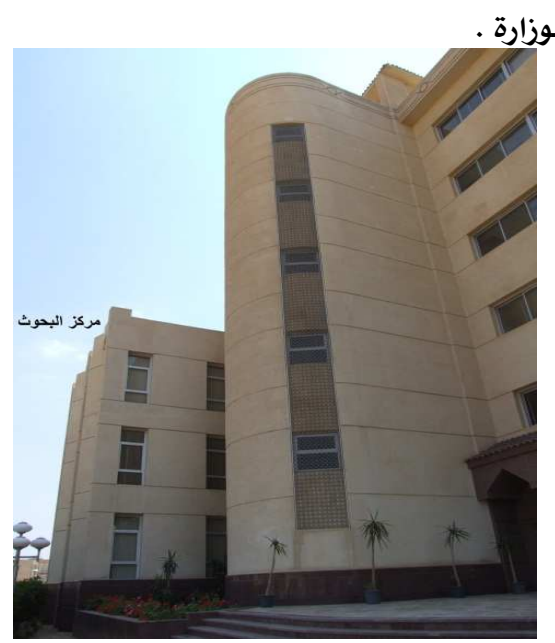

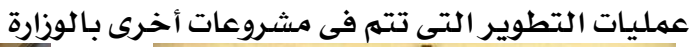
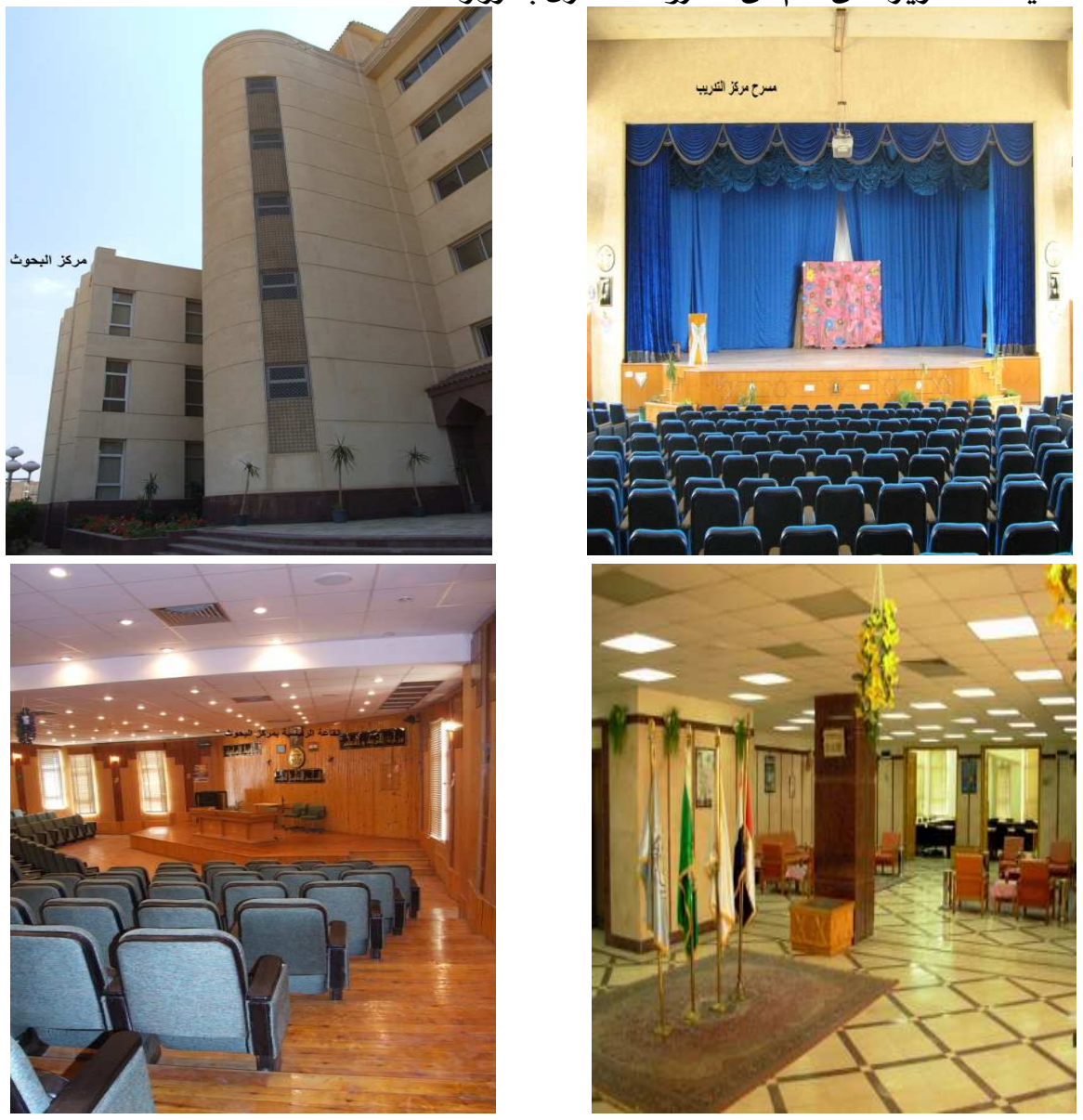

• دراسة استغلال موقع الوزارة وعرضده على الشركات بنظام حق الإنتفاع ·

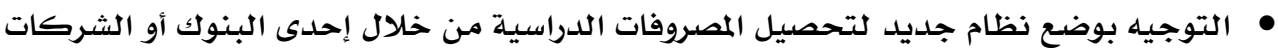

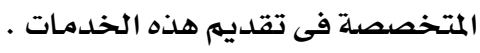

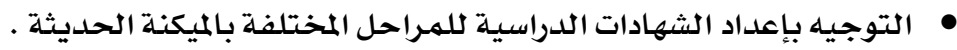

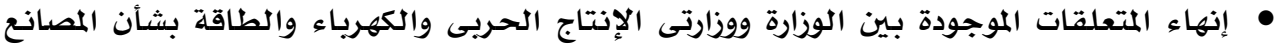

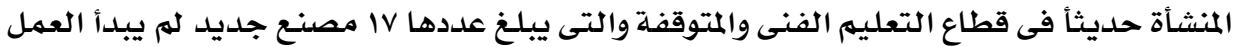




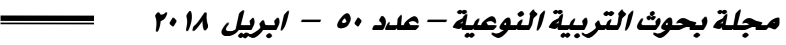

بها بعد نتيجة هذه المتعلقات، منها ل/ مصنع لأنتاج ألواح الطاقة الشمسية ولمبات الليد، وو

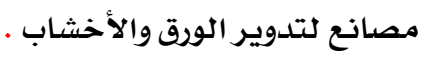
إتخاذ الإجراءات القانونية الكفيلة بالإستفادة من المقاصف المغلقة الموجودة بديوان عام الوزارة وعددها حوالى خمس مقاصف .

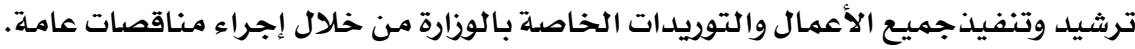

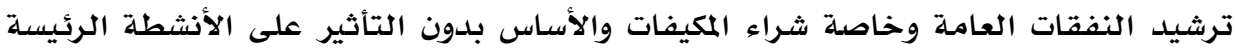
للوزارة . تلديد

بـد اءعديل بعض القرارات والموافقات المالية لتحقيق العدالة بين جميع العاملين بالوزارة ومنها :

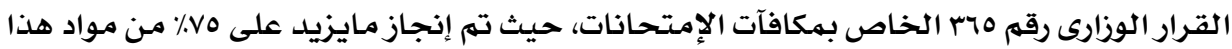

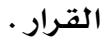

إعادة النظر فى صرف حافز إدارة الإتحادات الطلابية بما يحقق العدالة بين العاملين ويحقق الترشيد فى الوقت نفسـه. وقف الإزدواجية فى صرف المكافآت الامتحانية التى كانت تتمى (بموافقات تحت مسمى خارج

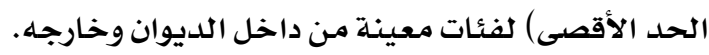

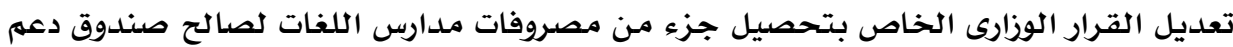

$$
\text { وتمويل المشروعات التعليمية. }
$$

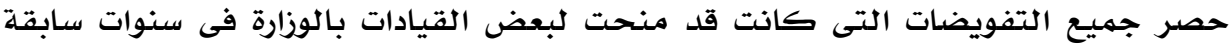

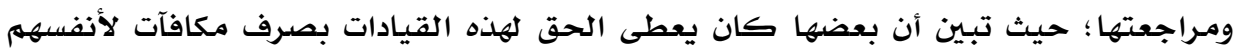

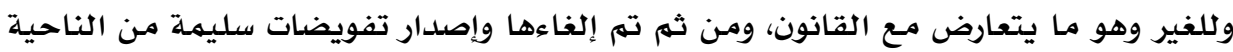

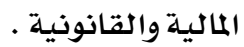

$$
\text { ترثيد بعض النفقات غير الضرورية، منها على سبيل المثال : }
$$

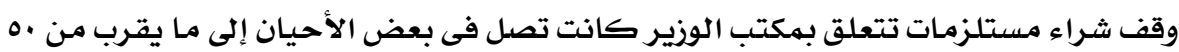

الف جنيه شهريا.

وقف شراء وجبات إفطار رمضانية يوميلة لما يقرب من 10 فردد من القيادات والأمن والعاملين

$$
\text { بالوزارة. }
$$

قصر شراء بدل صيفية وشتوية لعدد معين فقط من العاملين بمكتب الوزير تنطبق عليهم

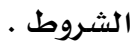

إلغاء ندب وتعاقدات عدد من المستشارين اتضح أنهم لا يقدمون أى إضافة حقيقية من خلال

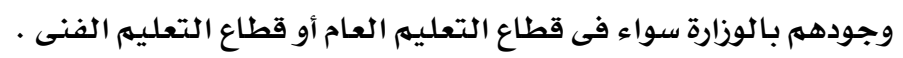

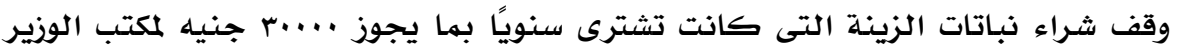
وكبار الموظفين بالديوان، مـع وجود صوبة زراعية داخل حرم ديوان الوزارة يعمل بها عدد من فن

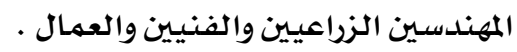

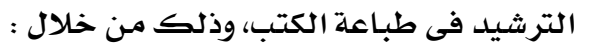


وقف طباعة كتاب اللغة الفرنسية الذى كان يوزع على طلاب المرحة الإعدادية فى حوالى 11 الفئل محافظة على سبيل التجربة واستمر تدريسه لحوالى تسع سنوات دون تقييم للتجريبة، والاكتفاء باسطوانه مد مـجة علئ.

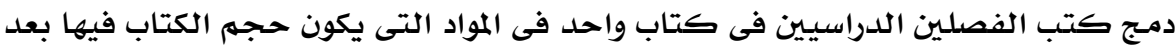

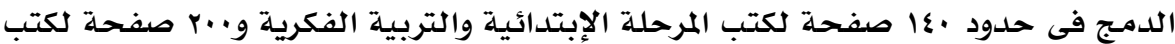
المرحلتين الإعلدادية والثانويـة. تعديل القرار الوزارى الخاص بترخيص الكتبد الكبل الخارجية بهما يحقق أفضل استفادة ممكنة للوزارة . ملتح

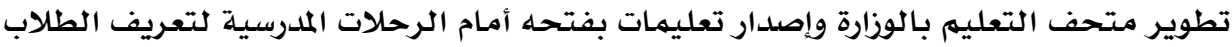

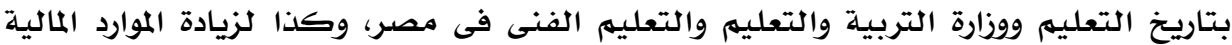
للمتحف .

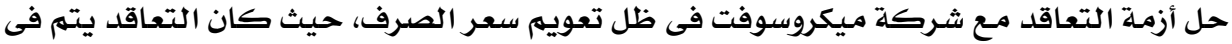

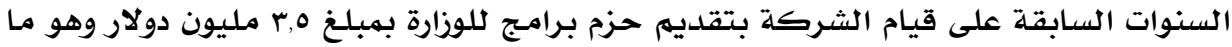

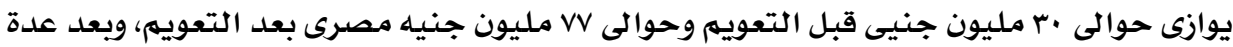

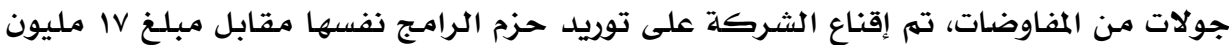

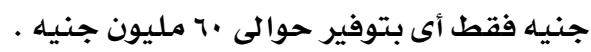

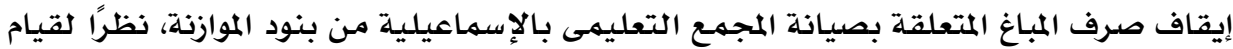

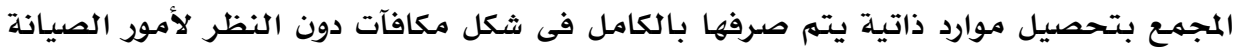

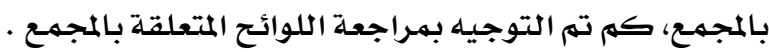

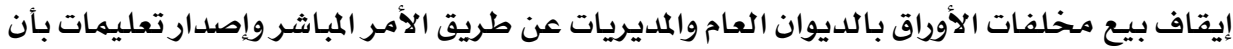
يتهم البيع عن طريق المزايدة العلنية أو عن طريق هيئة الخدمات الحكومية لتفادى التلاعب في فئي

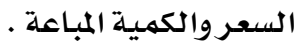
تكليف المستشار المالى بهراجعة كافة حسابات الوزارة، حيث تبين وجود ·r مليون جنياه تحصل

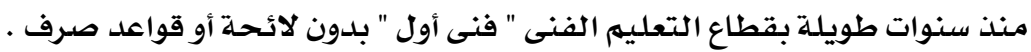

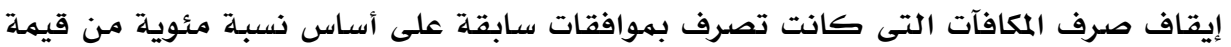

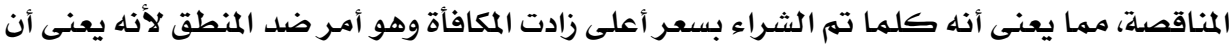

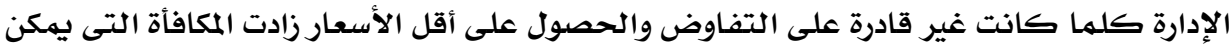
أن يحصلوا عليها الإدة أنسان. تحويل عدد كبير من القضايا إلى النيابة الإدارية والنيابة العامـة من الديوان العام والمديريات

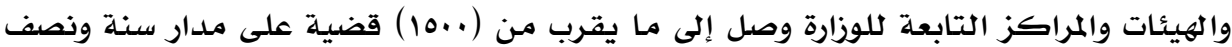

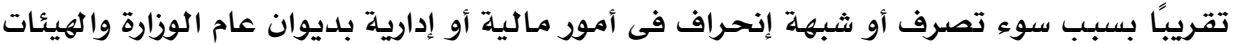
والمراكزوالمديريات التابعة له، منها على سبيل المثال لا الحصر : 
إحالة المتقاعصين من مديرى المديريات التعليمية عن تنفيذ الخطة الإستثمارية لجهات

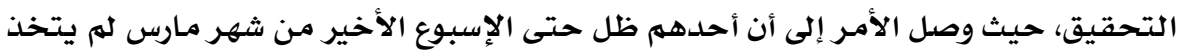

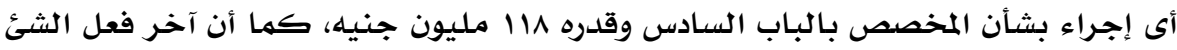

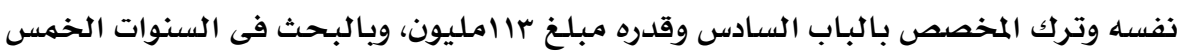

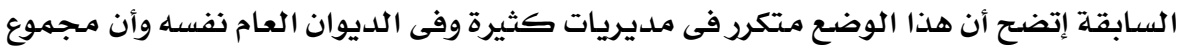

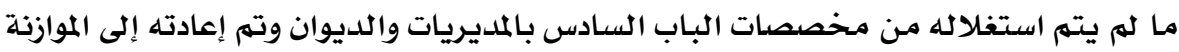

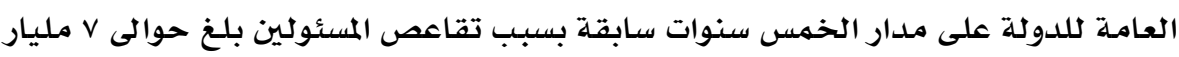

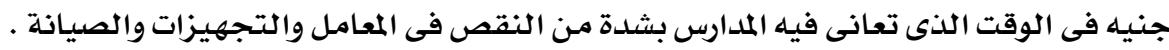

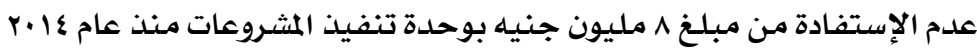

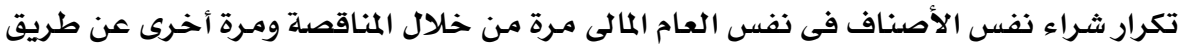

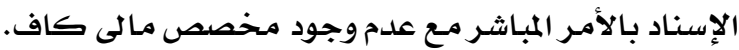

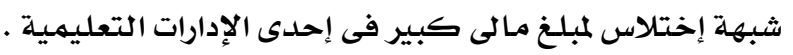

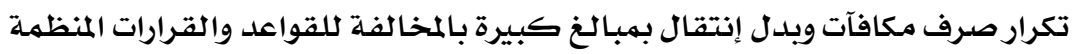

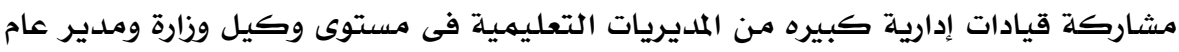

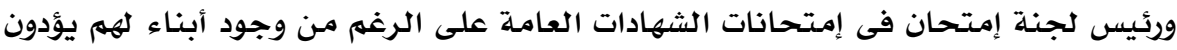

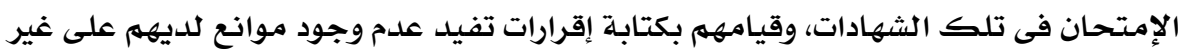
الحقيقة. قيام بعض المشاركين فى أعمال تصحيح الإمتحانات بتصوير أنفسهم أثناء عمليات

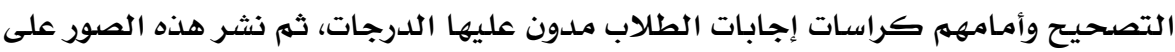

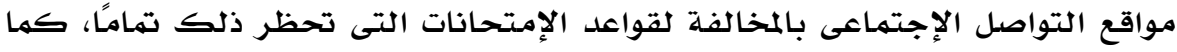

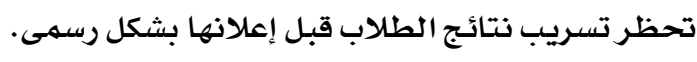

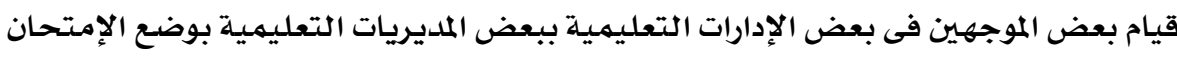

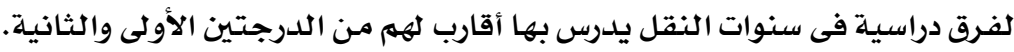

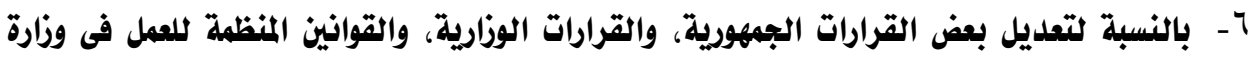

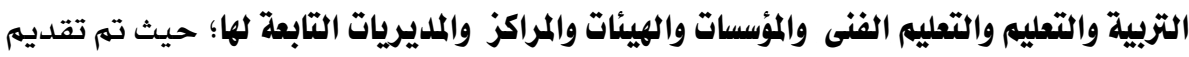

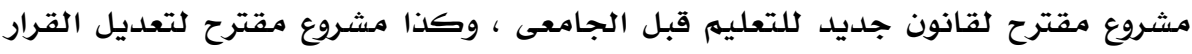

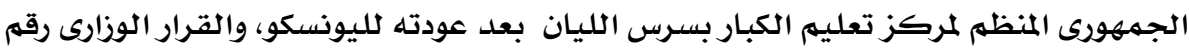

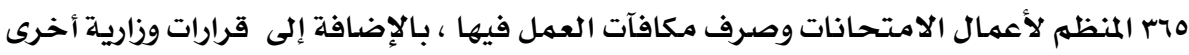

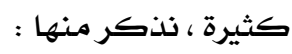
تعديل القرار الوزارى رقم •11 لسنـة ب999 الخاص بالمدارس المصريـه بالخارج تعديل القرار الوزارى رقم هبr الخاص بصرف مكافآت الامتحانات. 


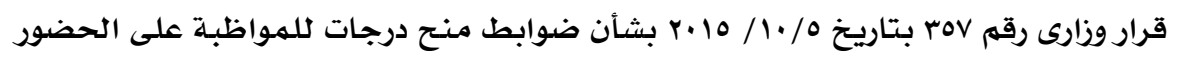

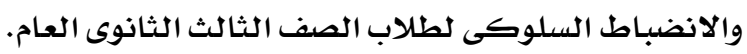

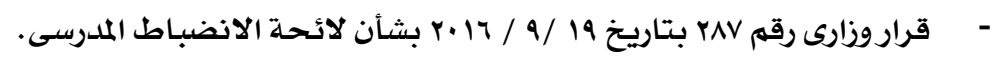

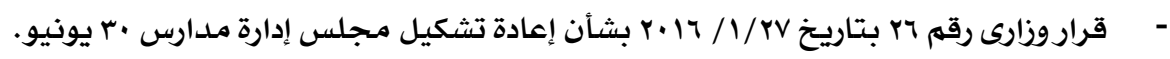

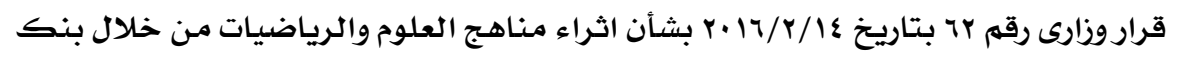
المعرفة.

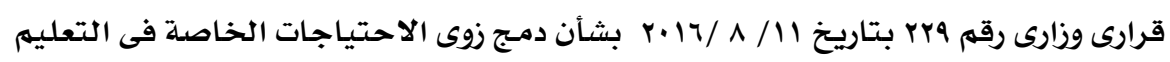

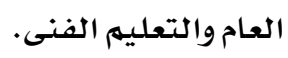

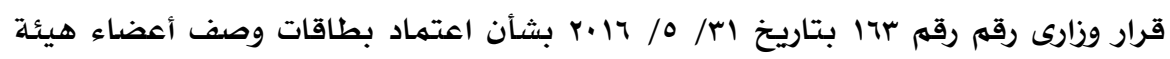
التعليهم

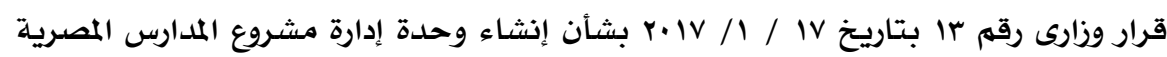

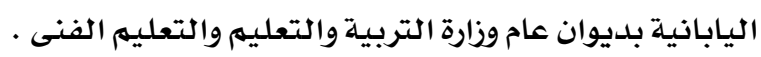

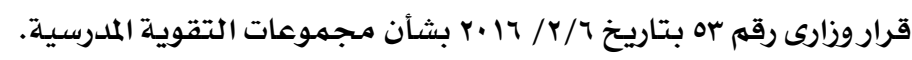

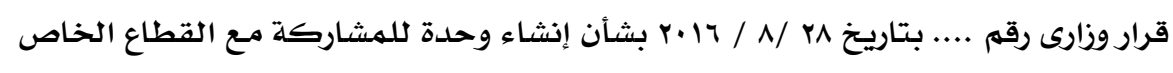

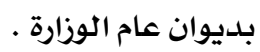

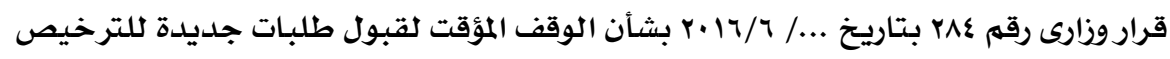

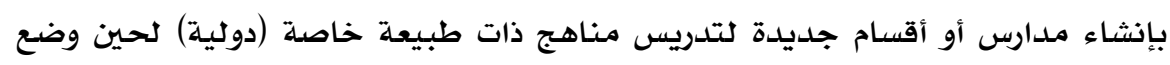
ضوابط تنظم عمل هذه النوعية مـن المدارس.

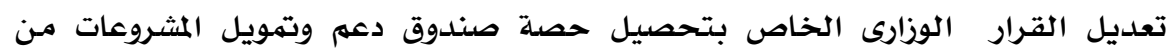

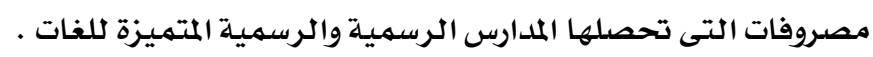

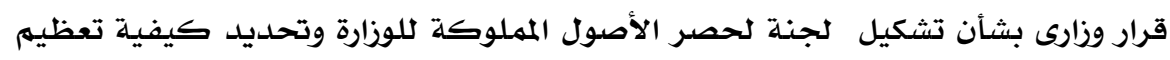

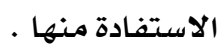

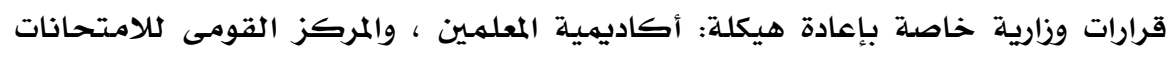

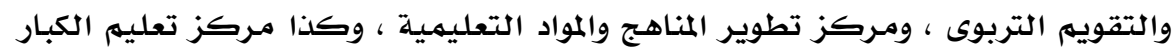
بسرس الليان. 